\title{
Long-Term Intracerebroventricular Infusion of Corticotropin- Releasing Hormone Alters Neuroendocrine, Neurochemical, Autonomic, Behavioral, and Cytokine Responses to a Systemic Inflammatory Challenge
}

\author{
Astrid C. E. Linthorst, ${ }^{1}$ Cornelia Flachskamm, ${ }^{1}$ Stephen J. Hopkins, ${ }^{2}$ Margaret E. Hoadley, ${ }^{2}$ Marta S. Labeur, ${ }^{1}$ \\ Florian Holsboer, ${ }^{1}$ and Johannes M. H. M. Reul ${ }^{1}$ \\ ${ }^{1}$ Max Planck Institute of Psychiatry, Clinical Institute, Department of Neuroendocrinology, Section \\ Neuroimmunoendocrinology, 80804 Munich, Germany, and 2University of Manchester Rheumatic Diseases Centre, \\ Clinical Sciences Building, Hope Hospital, Salford M6 8HD, United Kingdom
}

Corticotropin-releasing hormone $(\mathrm{CRH})$ was infused intracerebroventricularly into rats for $7 \mathrm{~d}$ via a miniosmotic pump (1 $\left.\mu \mathrm{g} \cdot \mu \mathrm{l}^{-1} \cdot \mathrm{hr}^{-1}\right)$. Body temperature and locomotor activity were recorded during the treatment using biotelemetry, whereas hippocampal serotonergic neurotransmission and free corticosterone levels were monitored using in vivo microdialysis on day 7 of $\mathrm{CRH}$ treatment. During the microdialysis experiment, behavioral activity was scored by assessing the time during which rats were active (locomotion, grooming, eating, drinking). Continuous intracerebroventricular infusion of $\mathrm{CRH}$ produced a transient increase in body temperature and locomotion. Moreover, intracerebroventricularly $\mathrm{CRH}$-treated rats showed elevated free corticosterone levels with no apparent diurnal rhythm.

Intraperitoneal administration of bacterial endotoxin [lipopolysaccharide (LPS); $100 \mu \mathrm{g} / \mathrm{kg}$ body weight] on day 7 of $\mathrm{CRH} /$ vehicle treatment produced a marked fever response in control animals, which was significantly blunted in intracerebroventricularly $\mathrm{CRH}$-treated rats. Although free corticosterone levels reached similar peak concentrations in both intracerebroventricularly vehicle- and $\mathrm{CRH}$-infused groups after LPS, this response was delayed significantly by $\sim 1 \mathrm{hr}$ in the intracerebroventricu- larly $\mathrm{CRH}$-treated animals. Microdialysis experiments showed no changes in basal extracellular levels of serotonin and 5-hydroxyindoleacetic acid in intracerebroventricularly $\mathrm{CRH}$ infused animals. Injection of LPS in intracerebroventricularly $\mathrm{CRH}-$ treated rats produced a blunted $5-\mathrm{HT}$ response and a delayed onset of behavioral inhibition and other signs of sickness behavior. Assessment of the endotoxin-induced cytokine responses showed significantly enhanced plasma interleukin-1 (IL-1) and IL-6 bioactivities in the intracerebroventricularly $\mathrm{CRH}$-infused animals $3 \mathrm{hr}$ after injection of LPS, whereas tumor necrosis factor bioactivity responses were not different.

Our data demonstrate that chronically elevated brain $\mathrm{CRH}$ levels produce marked changes in basal (largely $\mathrm{CRH}$ regulated) physiological and behavioral processes accompanied by aberrant responses to an acute challenge. The present study provides evidence that chronic $\mathrm{CRH}$ hypersecretion is an important factor in the etiology of stress-related disorders.

Key words: corticotropin-releasing hormone; endotoxin; hypothalamic-pituitary-adrenocortical axis; corticosterone; body temperature; sickness behavior; locomotion; serotonin; hippocampus; interleukin-1; interleukin-6; in vivo microdialysis; biotelemetry; rat
Corticotropin-releasing hormone $(\mathrm{CRH})$ is widely distributed throughout the brain and acts as a putative neurotransmitter/ modulator within the CNS. In the brain, $\mathrm{CRH}$ operates as an initiator of biological responses induced by stress, including effects on the hypothalamic-pituitary-adrenocortical (HPA) axis (Vale et al., 1981; Rivier et al., 1982; Rivier and Vale, 1983), the autonomic nervous system (Brown et al., 1982), and behavior (Britton et al., 1982; Sutton et al., 1982). Current evidence suggests that CRH acts as an important mediator of peripheral inflammatory stimuli at the level of the CNS. Interleukin-1 (IL-1), which is induced after intraperitoneal bacterial endotoxin injection [lipopolysac-

Received Feb. 5, 1997; revised March 12, 1997; accepted March 21, 1997.

This study was subsidized by the Volkswagen Stiftung (I/70 543) and the Biomed Concerted Actions Program "Cytokines in the brain." We thank Dr. A. Yassouridis for expert advice on the statistical analyses and Ms. S. Andres for technical assistance. Part of this work was presented at the 25th Annual Meeting of the Society for Neuroscience, 1995, San Diego, CA.

Correspondence should be addressed to Dr. J. M. H. M. Reul, Max Planck Institute of Psychiatry, Clinical Institute, Department of Neuroendocrinology, Section Neuroimmunoendocrinology, Kraepelinstrasse 2, 80804 Munich, Germany.

Copyright (C) 1997 Society for Neuroscience $0270-6474 / 97 / 174448-13 \$ 05.00 / 0$ charide (LPS)], was found to stimulate the HPA axis via activation of central CRH neurons (Berkenbosch et al., 1987; Sapolsky et al., 1987). Moreover, IL-1-induced fever has been shown to involve a central action of CRH (Rothwell, 1989).

Chronically increased central $\mathrm{CRH}$ drive, such as that occurring during chronic stress, may be regarded as potentially detrimental to health. Indeed, patients suffering from major depression show elevated levels of CRH in the cerebrospinal fluid (Nemeroff et al., 1984), increased numbers of $\mathrm{CRH}$ and $\mathrm{CRH} /$ vasopressinexpressing neurons in their paraventricular nucleus (PVN) (Raadsheer et al., 1994), elevated CRH mRNA levels in this hypothalamic nucleus (Raadsheer et al., 1995), and reduced CRH receptor density in the frontal cortex (Owens and Nemeroff, 1993). In addition, these patients show many symptoms reminiscent of the effects of centrally administered $\mathrm{CRH}$ in experimental animals, such as elevated levels of plasma cortisol, autonomic disturbances, anxiety, increased emotionality, and loss of appetite and sexual interest (Owens and Nemeroff, 1991; Holsboer and Barden, 1996). Depressed patients also show blunted ACTH 
Table 1. Effect of long-term administration of CRH on body weight gain and thymus weight

\begin{tabular}{lccc} 
& $\begin{array}{l}\text { Intracerebroventricular } \\
\text { vehicle }(n=26)\end{array}$ & $\begin{array}{l}\text { Intracerebroventricular } \\
\text { CRH }(n=21)\end{array}$ & $\begin{array}{l}\text { Subcutaneous } \\
\text { CRH }(n=10)\end{array}$ \\
\hline Body weight gain $(\mathrm{gm})$ & $25.2 \pm 4.2$ & $-9.0 \pm 3.4^{*, \#}$ & $23.9 \pm 4.0$ \\
Thymus weight $(\mathrm{mg})$ & $596.3 \pm 30.4$ & $243.5 \pm 14.0^{*}$ & $297.4 \pm 44.6^{*}$ \\
\hline
\end{tabular}

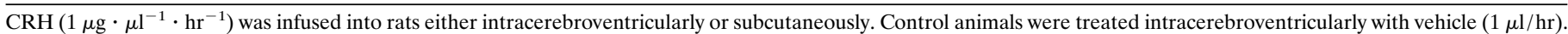

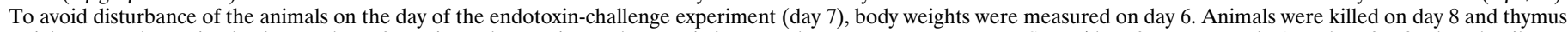

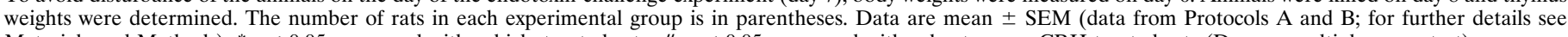
Materials and Methods). ${ }^{*} p<0.05$ compared with vehicle-treated rats; \# $p<0.05$ compared with subcutaneous CRH-treated rats (Duncan multiple range test).

responses to intravenously injected CRH (Holsboer et al., 1984; Gold et al., 1986). Until now, however, studies in humans could not identify which, if any, physiological and behavioral abnormalities associated with stress-related disorders were caused by hypersecretion of CRH. In addition, it is unknown how CRH hypersecretion relates to the well described disturbances in brain serotonergic metabolism in major depression (Maes and Meltzer, 1995). The purpose of this study was to further our understanding of the cause-and-effect relationships between hypersecretion of $\mathrm{CRH}$ and neurochemical, autonomic, behavioral, and immune system disturbances associated with complex stress-related disorders.

In the present study, we mimicked chronic central hypersecretion of CRH by continuous intracerebroventricular infusion of the peptide into rats. Previously, we have shown that this treatment induces chronic stress-like changes, such as elevated plasma ACTH and corticosterone levels, increased anterior pituitary proopiomelanocortin mRNA levels, thymus involution, adrenal hyperplasia, and immunosuppression (Labeur et al., 1995). To investigate changes in central CRH-regulated processes as a result of chronic CRH treatment, we studied (1) whether changes in baseline body temperature and locomotor activity occur during the period of continuous intracerebroventricular $\mathrm{CRH}$ infusion; (2) whether long-term intracerebroventricular $\mathrm{CRH}$ infusion results in aberrant responses to a subsequent acute stimulus (i.e., systemic injection of LPS), in terms of hippocampal serotonergic neurotransmission, fever, HPA axis activation, and (sickness) behavior; and (3) whether the altered physiological, neurochemical, and behavioral responses induced by LPS can be explained by changes in plasma IL-1, IL-6, and tumor necrosis factor (TNF) levels.

\section{MATERIALS AND METHODS \\ Animals}

Male Wistar rats were purchased from Charles River Wiga, Sulzfeld, Germany. Rats were housed six per cage under standard housing conditions (lights on from 7:30 A.M.-7:30 P.M.; temperature $22^{\circ} \mathrm{C}$; relative humidity $40-60 \%$ ) and had free access to food and water. At the time of surgery, the body weight was $\sim 250 \mathrm{gm}$. Animals were weighed and handled once per day ( 5 min per rat) starting 1 week before surgery. After the surgery, rats were moved to the experimental room (with similar environmental conditions as in the animal room facilities).

The experimental protocols were approved by the Ethical Committee on Animal Care and Use of the Government of Bavaria, Germany.

\section{Surgical procedures and treatments}

Four hours before the start of surgery (day 0 ), Alzet miniosmotic pumps (model 2001, Alza Corporation, Palo Alto, CA) were filled with vehicle or $\mathrm{CRH}$ solution and placed in sterile, pyrogen-free saline at $37^{\circ} \mathrm{C}$. $\mathrm{CRH}$ (human, rat; $1 \mu \mathrm{g} / \mu \mathrm{l}$ ) was dissolved in sterile, pyrogen-free saline containing $0.05 \%$ ascorbic acid. Control rats received the vehicle. The pumping rate of the miniosmotic pumps was $1 \mu \mathrm{l} / \mathrm{hr}$. Rats were treated with CRH or vehicle for $7 \mathrm{~d}$.

A stainless steel guide cannula (Alza) was implanted in the left lateral ventricle under halothane anesthesia (Protocols A, B and C; see below), as published previously (Labeur et al., 1995). The cannula was connected with polyethylene tubing to the miniosmotic pump, which was positioned subcutaneously in the dorsal region of the rat. In some animals only a miniosmotic pump was implanted subcutaneously for systemic delivery of $\mathrm{CRH}$.

For the experiments described under Protocols A and B, rats were additionally prepared for biotelemetry and in vivo microdialysis, respectively. For biotelemetry, a battery-powered transmitter for radiotelemetric measurement of body temperature and locomotor activity (Data Sciences International, St. Paul, MN) was implanted in the peritoneal cavity of the animal (Protocol A). For in vivo microdialysis (Protocol B), a guide cannula (CMA/12, CMA/Microdialysis AB, Stockholm, Sweden) was implanted in the brain, just entering the hippocampus at the dorsal site. Coordinates according to the atlas of Paxinos and Watson (1982) with the toothbar set at $-3.3 \mathrm{~mm}$, were lateral $5.2 \mathrm{~mm}$, posterior $5.1 \mathrm{~mm}$, and ventral $4.0 \mathrm{~mm}$ with bregma as an overall zero. For further details, see Linthorst et al. (1995a,b).

After surgery, rats were housed individually (Protocols A and B) in special plexiglass cages (length $\times$ width $\times$ height $=25 \times 25 \times 35 \mathrm{~cm}$ ) such that they could see, hear, and smell one another, and with food and water ad libitum. Rats used for the experiments described under Protocol $\mathrm{C}$ were housed three per cage after the surgery (length $\times$ width $\times$ height $=60 \times 38 \times 19 \mathrm{~cm})$.

\section{Experimental procedures}

Protocol A: biotelemetry. A computer-controlled automatic biotelemetry system (Data Sciences International) was used essentially as described previously (Linthorst et al., 1995a). Every 2 min, body temperature was measured and the accumulated locomotor activity score for the respective time interval was recorded. All measurements were then averaged over 30 min intervals. Recording started at lights off $1 \mathrm{~d}$ after surgery (day 1 ) and continued until day 8 . The first $24 \mathrm{hr}$ after the surgery were not included in the analyses to avoid interference of surgery/anesthesia-induced effects.

On day 7 of treatment (11:30 A.M.) rats were injected intraperitoneally either with sterile, pyrogen-free saline $(1 \mathrm{ml} / \mathrm{kg}$ body weight $)$ or with bacterial endotoxin (Salmonella abortus equi; $100 \mu \mathrm{g} / \mathrm{kg}$ body weight, dissolved in sterile, pyrogen-free saline and diluted to a volume of 1.0 $\mathrm{ml} / \mathrm{kg}$ body weight). This dose of LPS was shown to be effective in increasing body temperature and in stimulating HPA axis activity and distinct neurotransmitter systems in the brain (Linthorst et al., 1995a,b, 1996). After the injection, biotelemetric recording continued until 9 A.M. on day 8.

Protocol B: in vivo microdialysis. On day 5 of the intracerebroventricular treatment, a microdialysis probe with a length of $4 \mathrm{~mm}(\mathrm{CMA} / 12$, CMA Microdialysis AB, Stockholm, Sweden) (molecular weight cutoff $20,000 \mathrm{Da}$; outer diameter $0.5 \mathrm{~mm}$ ) was inserted slowly into the hippocampus under light halothane anesthesia, after which the animals where connected to a liquid swivel attached to a counterbalancing arm. Microdialysis experiments were started at 9 A.M. on day 7 of treatment and performed as described previously (Linthorst et al., 1995b). Samples were collected in a vial on top of the swivel. Collection vials were exchanged every $30 \mathrm{~min}$ (perfusion rate $2 \mu \mathrm{l} / \mathrm{min}$ ). The dialysate was divided into two parts for the measurement of 5-HT and 5-HIAA and for the determination of corticosterone. An aliquot of $25 \mu \mathrm{l}$ was taken and mixed with $20 \mu 10.025 \mathrm{M}$ acetic acid. This mixture was used for measurement of 5-HT and 5-HIAA by HPLC with electrochemical detection (see below).The remaining part of the collected sample was stored at $-20^{\circ} \mathrm{C}$ for measurement of corticosterone by radioimmunoassay (see below).

During the sampling period, the behavioral activity of each animal was 


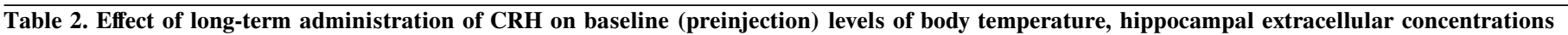
of 5-HT and 5-HIAA, free corticosterone, and behavioral activity on day 7 of treatment

\begin{tabular}{|c|c|c|c|}
\hline & $\begin{array}{l}\text { Intracerebroventricular } \\
\text { vehicle }\end{array}$ & $\begin{array}{l}\text { Intracerebroventricular } \\
\text { CRH }\end{array}$ & $\begin{array}{l}\text { Subcutaneous } \\
\text { CRH }\end{array}$ \\
\hline Body temperature $\left({ }^{\circ} \mathrm{C}\right)$ & $37.03 \pm 0.05(8)$ & $37.26 \pm 0.12(8)$ & $37.04 \pm 0.07(4)$ \\
\hline 5-HT (fmol/sample) & $15.27 \pm 1.41(12)$ & $16.33 \pm 1.13(11)$ & n.d. \\
\hline 5-HIAA (pmol/sample) & $11.06 \pm 0.60(13)$ & $10.76 \pm 0.55(11)$ & n.d. \\
\hline Free corticosterone $(\mu \mathrm{g} / \mathrm{dl})$ & $0.0065 \pm 0.0016(13)$ & $0.075 \pm 0.014(12)^{*}$ & n.d. \\
\hline Behavioral activity (arbitrary units) & $1.49 \pm 0.07(13)$ & $1.58 \pm 0.07(12)$ & n.d. \\
\hline
\end{tabular}

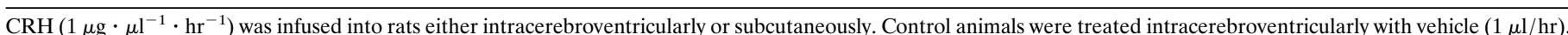

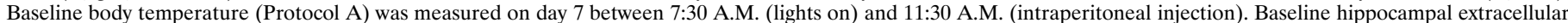

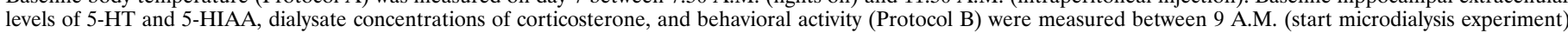

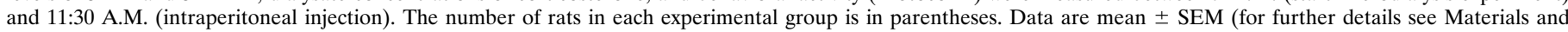
Methods). ${ }^{*} p<0.05$ compared with vehicle-treated rats (Student's $t$ test). n.d., Not determined.

observed, and therefore unexpected noise was avoided. A detailed description of the behavior (locomotor activity, rearing, grooming, eating, and drinking) was written down in a protocol. The behavioral activity was classified in three categories of arbitrary units (1-3), in which a behavioral activity of " 1 " meant that the rat was behaviorally active during $<2$ min of a 30 min period, " 2 " denoted activity during $>2$ min but $<15$ min of a $30 \mathrm{~min}$ period, and " 3 " indicated activity during $>15 \mathrm{~min}$ of a $30 \mathrm{~min}$ period. Behavioral scoring was conducted in a "blind" fashion, i.e., during scoring the observer was ignorant of any dialysate parameter value and regimen of treatment of any animal.

Five 30 min samples were collected between 9 and 11:30 A.M. for measurement of basal (preinjection) concentrations of 5-HT, 5-HIAA, and corticosterone. Next, rats were injected intraperitoneally with either sterile, pyrogen-free saline or LPS (for additional details, see Protocol A). After the injection, $30 \mathrm{~min}$ samples were collected for another $6 \mathrm{hr}$ (11:30 A.M.-5:30 P.M.).

Protocol C: collection of plasma for determination of cytokine concentrations. On day 7 of treatment, rats were injected intraperitoneally with saline or LPS at 11:30 A.M. (for additional details, see Protocol A). Rats were anesthetized quickly with an overdose of halothane at 3 or $6 \mathrm{hr}$ after the intraperitoneal injection. Next, the chest was opened and blood was collected by cardiac puncture into tubes containing heparin $(10 \mathrm{IU} / \mathrm{ml})$. Blood was centrifuged at $3000 \mathrm{rpm}$ for $15 \mathrm{~min}$ at $4^{\circ} \mathrm{C}$. Plasma samples were stored at $-80^{\circ} \mathrm{C}$ until assay. Plasma bioactivities of IL-1, IL-6, and TNF were determined by bioassay techniques (see below).

\section{Thymus collection and histology}

At the end of the experiments described under Protocols A and B (day 8), rats were killed and the thymus was removed and weighed. For histological verification of the position of the microdialysis probe, brains were collected in a $4 \%$ formalin solution and processed as described previously (Linthorst et al., 1995b). The position of the intracerebroventricular cannula was verified by the injection of trypan blue via the polyethylene tubing (Protocols A and B).

\section{Measurement of 5-HT and 5-HIAA}

Samples were assayed for 5-HT and 5-HIAA without prior purification using HPLC with electrochemical detection as described previously (Linthorst et al., 1994, 1995b).

\section{Measurement of corticosterone in the dialysates}

Microdialysis samples were assayed for corticosterone by radioimmunoassay (ICN Biomedicals, Costa Mesa, CA) as described earlier (Linthorst et al., 1994, 1995b). The detection limit of the assay was $0.001 \mu \mathrm{g} / \mathrm{dl}$.

\section{Cytokine bioassays}

IL-1 activity in plasma was measured using the D10(N4)M cell line, essentially as described previously (Hopkins and Humphreys, 1990). IL-6 bioactivity in plasma was measured using B-9 hybridoma cells, essentially as described by Luheshi et al. (1996). TNF bioactivity was measured by virtue of its cytolytic activity on actinomycin D-treated WEHI-164 cells over a period of $24 \mathrm{hr}$. This assay does not distinguish between TNF- $\alpha$ and TNF- $\beta$ (lymphotoxin). For all assays, the cell viability was determined as described previously (Holt et al., 1991). Cytokine units are referenced to the first international standards for human IL-6 (89/548) and human IL-1 $\beta(86 / 680)$, and a recombinant murine TNF- $\alpha$ standard
(88/532) from the National Institute for Biological Standards and Control (NIBSC, South Mimms, UK). Serial dilutions of samples and standards were made in tissue culture medium. Activity was determined where sample and standard dilution curves were parallel. The detection limits of the assays were between 3 and $9 \mathrm{IU} / \mathrm{ml}$ for IL-6, $0.25 \mathrm{IU} / \mathrm{ml}$ for IL-1, and an equivalent of $1.25 \mathrm{pg} / \mathrm{ml}$ of standard murine TNF- $\alpha$, after allowing for dilution of samples to avoid nonspecific interference $(1 / 8,1 / 54$, and $1 / 6$ for IL-1, IL-6, and TNF, respectively). Detection limits took the dilution of plasma into account (limit of detection for samples $=$ limit of detection for standard cytokine $x$ initial sample dilution or dilution at which sample responses became nonparallel) and were therefore higher than for standard cytokine in medium.

\section{Materials}

CRH (rat, human) was purchased from Bachem (Heidelberg, Germany). LPS (Salmonella abortus equi, catalog no. L-6636) was obtained from Sigma (St. Louis, MO). All other reagents used were analytical grade.

\section{Calculations and statistical procedures}

All results are expressed as mean \pm SEM. As level of significance, $\alpha<$ 0.05 was accepted. Data on body weight gain and thymus weight were analyzed by one-way ANOVA (ONEWAY) followed by a Duncan multiple range test. The effects of subcutaneous infusion of $\mathrm{CRH}$ were compared with intracerebroventricular vehicle infusion, because preliminary data had indicated that there were no differences between intracerebroventricularly vehicle-treated rats and subcutaneously vehicletreated rats (A. C. E. Linthorst and J. M. H. M. Reul, unpublished observations).

Protocol $A$. The $24 \mathrm{hr}$ of the day were divided into four periods of $6 \mathrm{hr}$. Next, the $6 \mathrm{hr}$ period mean values of body temperature and locomotor activity were analyzed by multivariate ANOVA (MANOVA) with repeated measures design with treatment as the between subject factor and time as the within subject factor. For further analyses, post hoc Student's $t$ tests were performed.

On day 7 of $\mathrm{CRH}$ treatment, rats were given an intraperitoneal injection of saline or LPS at 11:30 A.M., and body temperature and locomotion were recorded until 9 A.M. on day 8 . First, baseline values for body temperature and locomotor activity were calculated using the data obtained between 7:30 and 11:30 A.M., which were tested with ONEWAY and Duncan multiple range test. Then, to exclude effects of differences in baseline body temperature, $\delta$ values for body temperature were calculated for each animal by subtracting the mean baseline body temperature from the absolute body temperature data. Two-way MANOVA with repeated measures design was used to evaluate the effects of saline and LPS on body temperature and locomotor activity (with pretreatment and treatment as between subject factors and time as within subject factor). For this purpose the period after the injection was divided into two periods, i.e., the lights-on and lights-off period. To further explore significant differences between data of specified time periods, the time period from 7:30 A.M. on day 7 to 7:30 A.M. on day 8 of treatment was divided into six periods of $4 \mathrm{hr}$ each and statistically tested with MANOVA with repeated measures design.

Protocol B. First, for each saline-injected rat, mean extracellular concentrations of 5-HT and 5-HIAA were calculated for each behavioral activity score $(1,2,3)$ using data from the whole time curve. MANOVA with repeated measures design was used to determine whether overall 
A
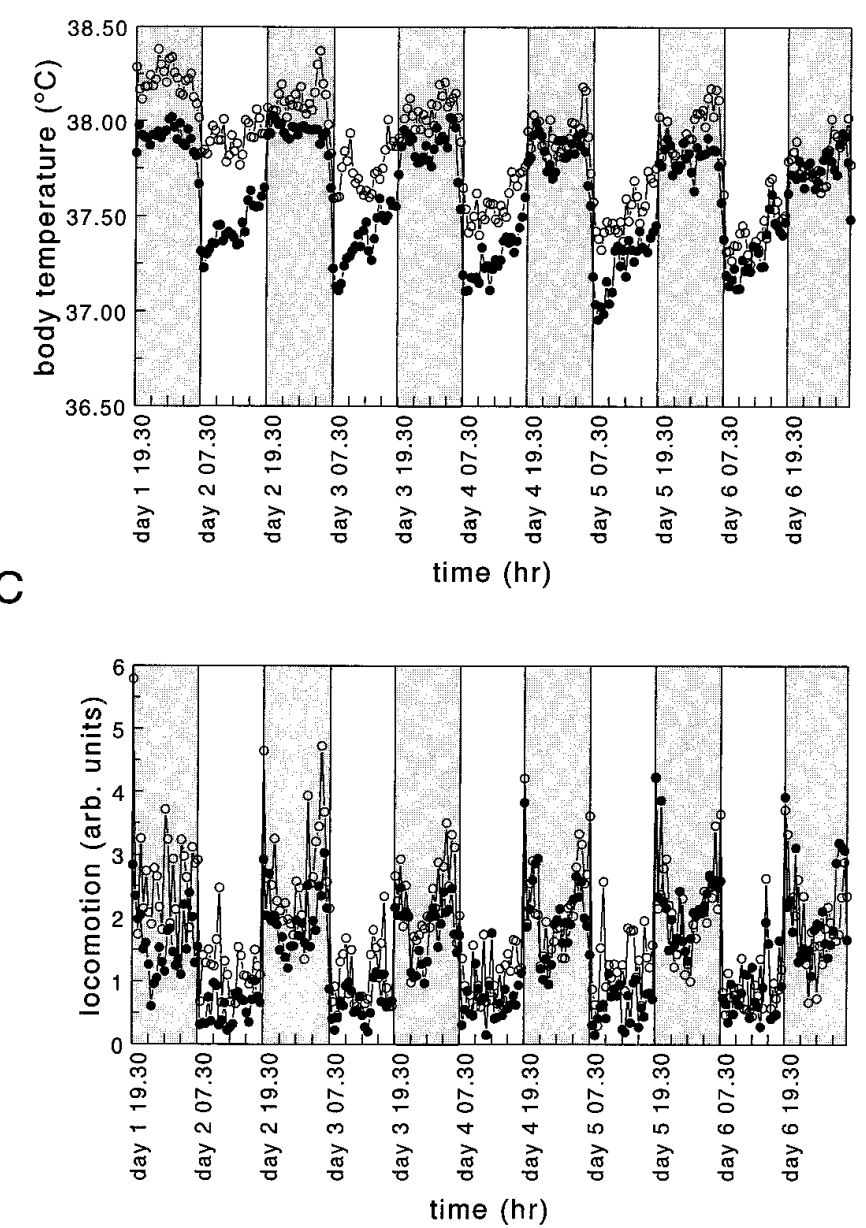

B

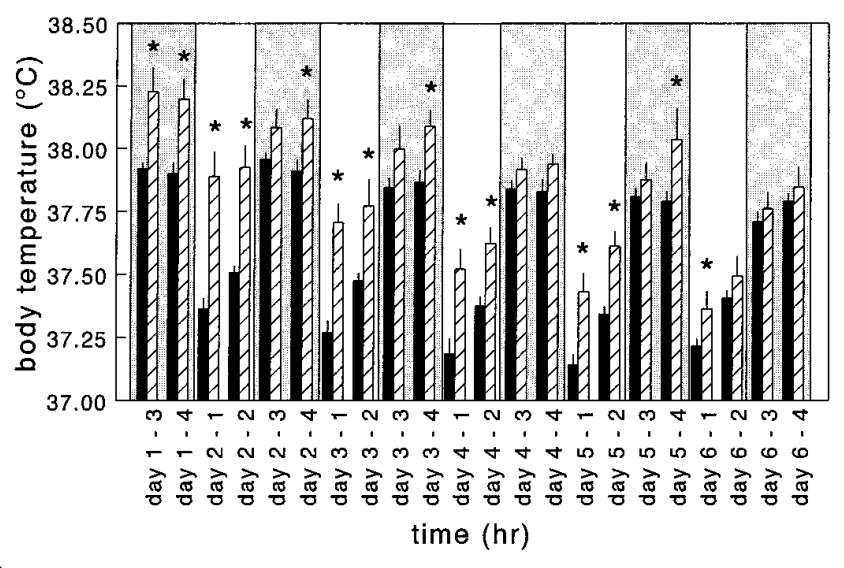

D

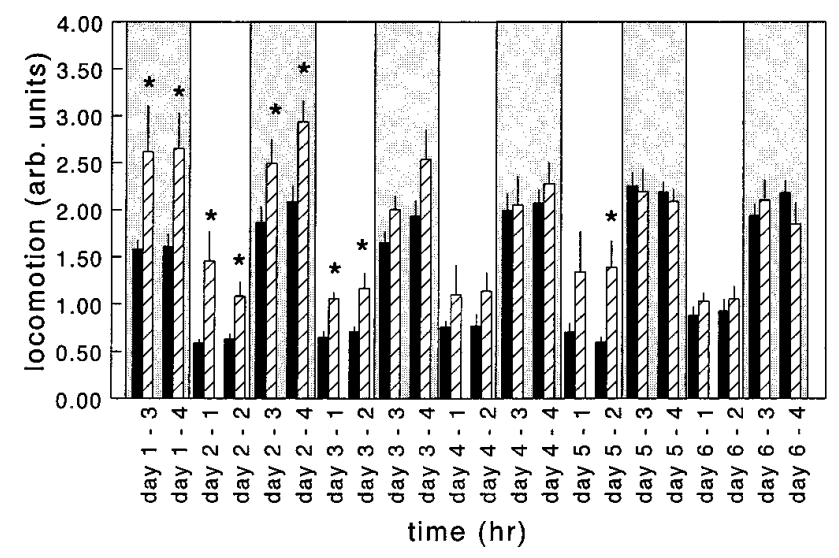

Figure 1. Effects of long-term intracerebroventricular infusion of CRH on the circadian rhythms of body temperature $(A, B)$ and locomotor activity $(C$, $D$ ) in rats (Protocol A). Body temperature $\left({ }^{\circ} \mathrm{C}\right)$ and locomotor activity (arbitrary units) were measured continuously during $6 \mathrm{~d}$ of treatment with use of biotelemetry. The shaded areas indicate the dark periods. The data shown in $A$ and $C$ represent means over 30 min [0, intracerebroventricularly vehicle-treated control rats $(n=12)$; $\bigcirc$, intracerebroventricularly CRH-treated rats $(n=9)$; SEM values were omitted for the sake of clarity]. The time points on the $x$-axis correspond to the time of the day at which collection of the $30 \mathrm{~min}$ sample was started. The data depicted in $B$ and $D$ represent mean \pm SEM over $6 \mathrm{hr}$ (closed bars, intracerebroventricularly vehicle-treated rats; hatched bars, intracerebroventricularly CRH-treated rats). For this purpose, the $24 \mathrm{hr}$ of the day were divided into four periods of $6 \mathrm{hr}$, of which periods 1 and 2 denote the light phase and periods 3 and 4 represent the dark phase (as shown on the $x$-axis). For more details see Materials and Methods. *, Significantly different from intracerebroventricularly vehicle-treated rats (Student's $t$ test). For additional statistical analyses, see Results.

significant differences existed between the extracellular concentrations of 5-HT and 5-HIAA at different behavioral activity scores. If a significant main effect of behavioral activity was found, an additional trend analysis with polynomial contrasts within MANOVA was performed to obtain the curve form that fitted the means of these variables (5-HT, 5-HIAA) with behavioral activity. Paired $t$ tests were performed to assess separate statistical differences between 5-HT or 5-HIAA levels at their respective behavioral activity scores. Putative differences in the extracellular concentrations of 5-HT and 5-HIAA at the different behavioral activity scores between vehicle- and CRH-infused rats were evaluated with Student's $t$ tests.

Second, baseline values were calculated for free corticosterone levels, extracellular concentrations of 5-HT and 5-HIAA, and behavioral activity, using data collected between 9 and 11:30 A.M. For 5-HT and 5-HIAA, only data obtained at behavioral activity score 1 were used. Baseline values of intracerebroventricularly vehicle- and intracerebroventricularly CRH-treated rats were analyzed using Student's $t$ test. Next, extracellular concentrations of 5-HT and 5-HIAA were expressed as percentage of baseline for each individual rat. MANOVA with repeated measures design was used to evaluate the effects of intracerebroventricular $\mathrm{CRH}$ treatment on corticosterone levels (with pretreatment as be- tween subject factor and time as within subject factor). Moreover, twoway MANOVA with repeated measures design was used to analyze the effects of saline and LPS on corticosterone, 5-HT, 5-HIAA, and behavioral activity in vehicle- and CRH-treated rats (with pretreatment and treatment as between subject factors and time as within subject factor). The first time point showing a statistically significant LPS-induced change in corticosterone and 5-HIAA (compared with injection of saline) was assessed by Student's $t$ test. Differences in $n$ values are caused by incidental unsuccessful measurements of 5-HT (two rats) and 5-HIAA (one rat).

Protocol $C$. The effects of LPS on plasma levels of IL-6 and TNF in intracerebroventricularly vehicle- and intracerebroventricularly $\mathrm{CRH}$ infused rats were evaluated statistically using two-way ANOVA, with pretreatment and time after the injection as the between subject factors followed by post hoc Duncan analyses. The effect of saline was not evaluated, because in many samples cytokine levels were below detection. Because IL- 6 bioactivity values are not normally distributed, IL- 6 values were log-transformed before parametric ANOVA analysis was performed. Plasma levels of IL-1 at $3 \mathrm{hr}$ after LPS injection were tested by Student's $t$ test. 


\section{RESULTS}

\section{Effect of long-term intracerebroventricular infusion of CRH on body weight gain and thymus weight}

There were no significant differences in the initial body weights of the various treatment groups (data not shown). Long-term intracerebroventricular infusion of $\mathrm{CRH}$ caused a significant reduction in body weight gain and a pronounced involution of the thymus ( $\sim 60 \%$; Table 1). Although the intracerebroventricularly CRHtreated rats gained some weight during the second part of the infusion period (data not shown), this was not sufficient to overcome the initial decrease in body weight and to reach presurgery weights. Subcutaneous infusion of $\mathrm{CRH}$ produced no effect on body weight gain, but reduced thymus weight significantly $(\sim 50 \%$; Table 1). Thymus weights of rats treated intracerebroventricularly or subcutaneously with $\mathrm{CRH}$ were not significantly different, indicating that the net glucocorticoid exposure was similar in these experimental groups (Dallman et al., 1987).

\section{Effect of long-term intracerebroventricular infusion of CRH on the circadian rhythms of body temperature and locomotor activity (Protocol A)}

Control rats, intracerebroventricularly infused with vehicle, showed a distinct circadian rhythm in body temperature (Fig. $1 A$ ). Body temperature displayed its lowest levels during the first part of the light phase of the diurnal cycle and started to rise in the late afternoon, reaching its maximum levels $\sim 60$ min after the lights were switched off. Body temperature showed a rapid decrease, starting between 30 and $60 \mathrm{~min}$ before the lights were switched on. The difference between body temperature levels during the first 6 $\mathrm{hr}$ of the light phase and during the night was $\sim 0.6-0.7^{\circ} \mathrm{C}$ (Fig. $1 B$ ). Infusion of $\mathrm{CRH}$ intracerebroventricularly produced a pronounced elevation in mean body temperature levels during the light as well as the dark phase of the diurnal cycle (MANOVA with repeated measures, effect of treatment: $F_{(1,19)}=23.73$, significance of $F \leq 0.0005$ ) (Fig. $1 A, B$ ). Rats treated intracerebroventricularly with $\mathrm{CRH}$ showed a clear flattening of the diurnal rhythm in body temperature, as indicated by the reduced difference between day and night body temperature values $(\sim 0.2-$ $0.4^{\circ} \mathrm{C}$ ) (Fig. $1 \mathrm{~B}$ ), especially during the first $3-4 \mathrm{~d}$ of treatment. From the second quarter of day 6 on, no significant differences were seen (Fig. $1 B$ ).

Figure $1 C$ shows that locomotor activity of control rats displayed a pronounced circadian rhythm, with low levels during the light phase (resting/sleeping period of rats) and higher levels during the dark period. Intracerebroventricular infusion of $\mathrm{CRH}$, however, increased locomotor activity during both the light and dark period (MANOVA with repeated measures, effect of treatment: $F_{(1,19)}=8.68$, significance of $\left.F<0.01\right)($ Fig. $1 C, D)$. Locomotion was significantly enhanced by $\mathrm{CRH}$ only on days 1 and 2 and the light period of day 3 , whereas from the third quarter of day 3 , no statistically significant differences could be observed, with the exception of the second quarter of day 5 (Fig. 1D).

In contrast to intracerebroventricular infusion of $\mathrm{CRH}$, subcutaneous infusion of the peptide produced no significant changes in the circadian rhythms of body temperature and locomotion (data not shown).

\section{Effects of intraperitoneal administration of saline and LPS on body temperature in long-term $\mathrm{CRH}$-treated rats (Protocol A)}

On day 7 of intracerebroventricular infusion, the effects of intraperitoneal administration of saline and LPS on body temperature
A

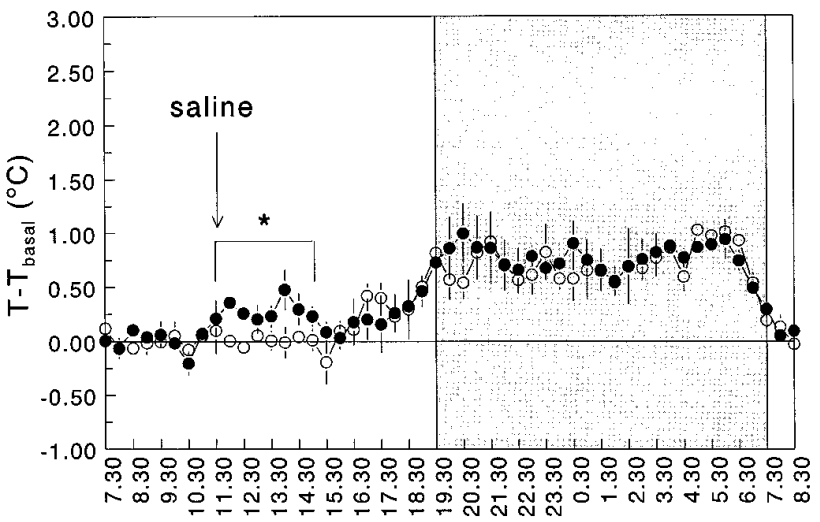

time (hr)

B

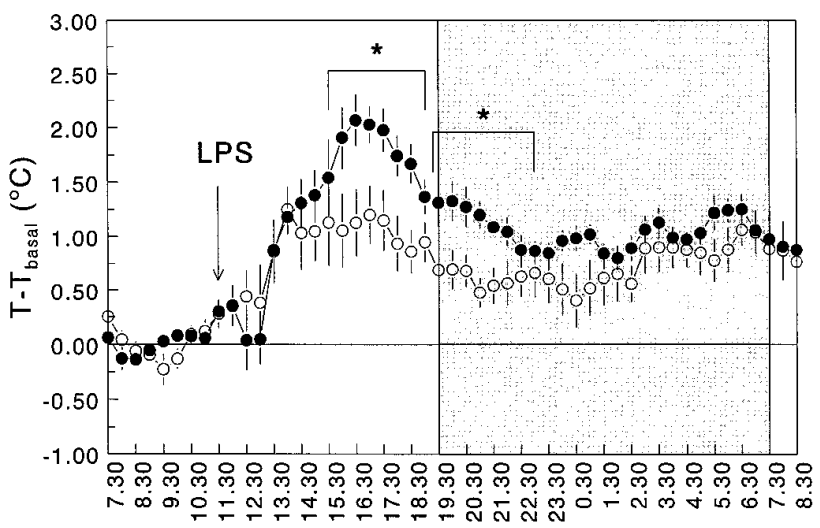

time (hr)

Figure 2. Effects of intraperitoneal administration of saline $(A)$ and LPS (B) $(100 \mu \mathrm{g} / \mathrm{kg}$ body weight $)$ on body temperature in long-term intracerebroventricularly vehicle-treated rats $(\bullet)$ and intracerebroventricularly $\mathrm{CRH}$-infused rats $(\bigcirc)$. Saline or LPS were injected at 11:30 A.M. on day 7 of the infusion treatment, as indicated by the arrow. Body temperature ( $\delta$ baseline) was monitored during $24 \mathrm{hr}$ starting at 7:30 A.M. on day 7. For more details see Materials and Methods. The time points on the $x$-axis correspond to the time of the day at which collection of the $30 \mathrm{~min}$ sample was started. The shaded area indicates the dark period. Values represent mean \pm SEM (intraperitoneally saline-injected groups, $n=3$; intraperitoneally LPS-injected groups, $n=5$ ). *, Significantly different from intracerebroventricularly vehicle-treated rats (MANOVA with repeated measures design). For additional statistical analyses, see Results.

were studied (Fig. 2). Baseline body temperature (7:30-11:30 A.M.) did not differ between the infusion groups (Table 2). MANOVA with repeated measures analysis on the body temperature responses during the light phase of the diurnal cycle of all four pretreatment/treatment groups (intracerebroventricular vehicle/intraperitoneal saline; intracerebroventricular vehicle/intraperitoneal LPS; intracerebroventricular CRH/intraperitoneal saline; intracerebroventricular $\mathrm{CRH} /$ intraperitoneal LPS) revealed a significant effect of treatment (saline or LPS) and a significant interaction between treatment and time $\left(F_{(1,12)}=19.52\right.$, significance of $F=0.001 ; F_{(15,180)}=10.62$, significance of $F \leq 0.0005$, respectively).

Intraperitoneal injection of saline in vehicle-treated rats caused a small, transient increase in body temperature $\left(\sim 0.25^{\circ} \mathrm{C}\right)$ (Fig. $2 A$ ). In contrast, intracerebroventricularly $\mathrm{CRH}$-infused rats 


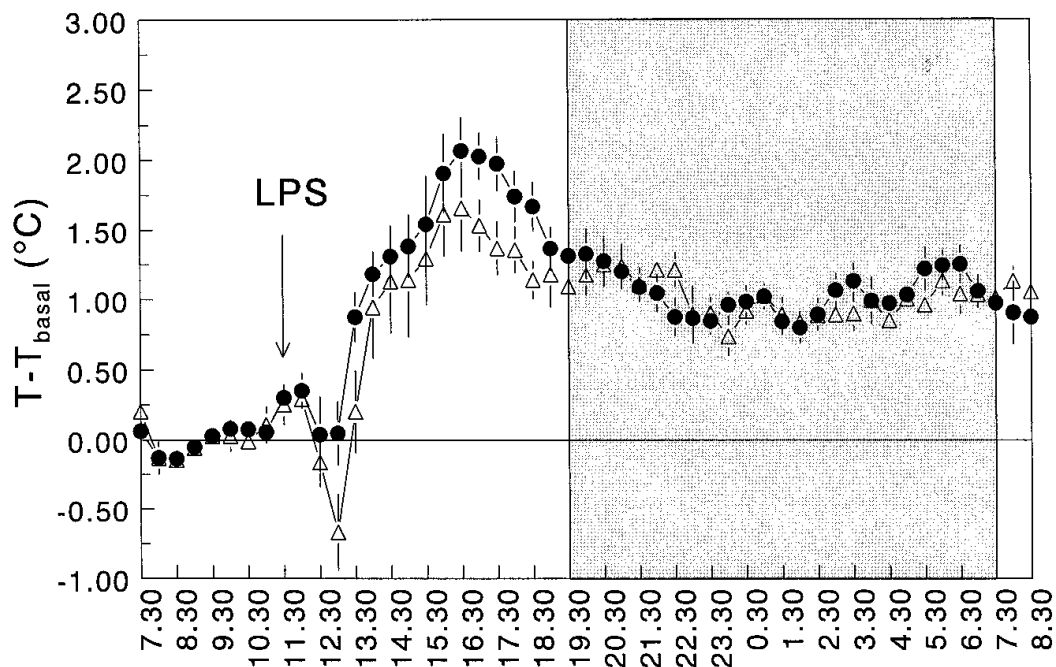

time (hr)
Figure 3. Effects of intraperitoneal administration of LPS $(100 \mu \mathrm{g} / \mathrm{kg}$ body weight) on body temperature in long-term intracerebroventricularly vehicle-infused rats $(\mathbf{0})$ and subcutaneously CRH-infused rats $(\triangle)$. For more details, see Materials and Methods and legend to Figure 2. Values represent mean \pm SEM (intracerebroventricular vehicle, $n=5$; subcutaneous $\mathrm{CRH}, n=4)$. For statistical analyses, see Results. showed no (stress-induced) increase in body temperature after an intraperitoneal injection of saline (Fig. 2A).

Intraperitoneal administration of LPS (100 $\mu \mathrm{g} / \mathrm{kg}$ body weight) caused a pronounced increase in body temperature in the intracerebroventricularly vehicle-infused rats. Body temperature started to increase between 120 and $150 \mathrm{~min}$ and reached maximal levels between 4.5 and $5.5 \mathrm{hr}$ postinjection (Fig. $2 \mathrm{~B}$ ). The body temperature response to LPS in intracerebroventricularly CRH-infused rats was significantly blunted as compared with that in the control animals (MANOVA with repeated measures analysis: interaction between pretreatment, treatment, and time: $F_{(15,180)}=4.11$, significance of $F \leq 0.0005$ ) (Fig. $2 B$ ). Moreover, during the first $4 \mathrm{hr}$ of the night period, body temperature was significantly lower in LPS-injected intracerebroventricularly CRH-treated rats than in LPS-injected control rats (Fig. 2B). After LPS, a similar reduction in locomotor activity (as determined by biotelemetric recording) was observed in intracerebroventricularly vehicle- and CRH-infused animals (data not shown). Both groups of animals also showed specific characteristics of sickness behavior, such as piloerection, a curled-up body posture, and relative immobility.

Intraperitoneal administration of LPS also caused fever (Fig. 3) and decreased locomotion (data not shown) in subcutaneously $\mathrm{CRH}$-infused rats. These effects, however, were not significantly different from those found in control rats (Fig. 3) (MANOVA with repeated measures; body temperature: light phase, effect of treatment $F_{(1,7)}=1.69$, significance of $F>0.05$; interaction between treatment and time $F_{(15,105)}=0.94$, significance of $F>$ 0.05 ; dark phase, effect of treatment $F_{(1,7)}=0.15$, significance of $F>0.05$; interaction between treatment and time $F_{(23,161)}=0.99$, significance of $F>0.05$ ).

\section{Effect of intraperitoneal administration of saline and LPS on free corticosterone levels in long-term CRH- treated rats (Protocol B)}

We used the microdialysis technique to measure corticosterone levels in the extracellular fluid. Because the extracellular fluid of the brain is devoid of corticosterone binding proteins, dialysate levels of corticosterone are a reflection of the biologically active free corticosterone fraction. As shown in Figure $4 A$, control rats showed a distinct diurnal rhythm in free corticosterone, with low levels during the morning and a subsequent rise starting between 1:30 and 2:00 P.M. Corticosterone levels were elevated, however,
( $\sim 10$ times) in rats long-term intracerebroventricularly infused with $\mathrm{CRH}$ (Fig. $4 A, B$, Table 2). These animals showed no apparent rhythm in free corticosterone, with overall levels similar to the late afternoon levels in control animals (Fig. 4A) (MANOVA with repeated measures design, effect of CRH: $F_{(1,10)}=5.74$, significance of $F<0.05$ ).

Intraperitoneal administration of saline produced no significant changes in free corticosterone levels in either animal group (Fig. 4A). Intraperitoneal injection of LPS, however, caused a dramatic increase in free corticosterone levels (MANOVA with repeated measures design, effect of treatment: $F_{(1,21)}=34.04$, significance of $\left.F \leq 0.0005\right)$ (Fig. $4 B$ ). These levels were approximately six times higher than those found during the late afternoon in the saline-injected groups. Although the maximal levels reached were not different between intracerebroventricularly vehicle- and intracerebroventricularly $\mathrm{CRH}$-infused rats, the response in the $\mathrm{CRH}$-infused animals was delayed significantly by $\sim 1 \mathrm{hr}$ (Fig. $4 B$ ).

\section{Serotonergic neurotransmission in the hippocampus in relation to behavioral activity (Protocol B)}

Extracellular levels of 5-HT and 5-HIAA were not different between intracerebroventricularly vehicle- and CRH-infused rats at the different behavioral activity scores (Fig. 5; also see Table 2). For both intracerebroventricularly vehicle- and $\mathrm{CRH}$-treated rats, a significant linear relationship between extracellular levels of 5-HT and behavioral activity was found (Figs. 5A,B, 6A,C) (MANOVA intracerebroventricularly vehicle-treated rats: $F_{(2,10)}$ $=70.91$, significance of $F \leq 0.0005$; polynomial contrast: linear trend, $t=9.39$, significance of $t \leq 0.0005$; MANOVA intracerebroventricularly CRH-treated rats: $F_{(2,8)}=12.19$, significance of $F<0.005$; polynomial contrast: linear trend, $t=3.64$, significance of $t<0.05$ ). A significant linear relationship was also found for hippocampal extracellular levels of 5-HIAA for both infusion groups (Fig. 5C,D) (MANOVA vehicle-treated rats: $F_{(2,10)}=$ 4.68, significance of $F<0.05$; polynomial contrast: linear trend, $t=2.88$, significance of $t<0.05$; MANOVA CRH-treated rats: $F_{(2,8)}=6.39$, significance of $F<0.05$; polynomial contrast: linear trend, $t=3.80$, significance of $t<0.02$ ). However, although the differences in extracellular concentrations of 5-HIAA at different behavioral activity stages were only minute, pronounced increases in hippocampal 5-HT were found at activities 2 and 3 (Fig. 5). 
A

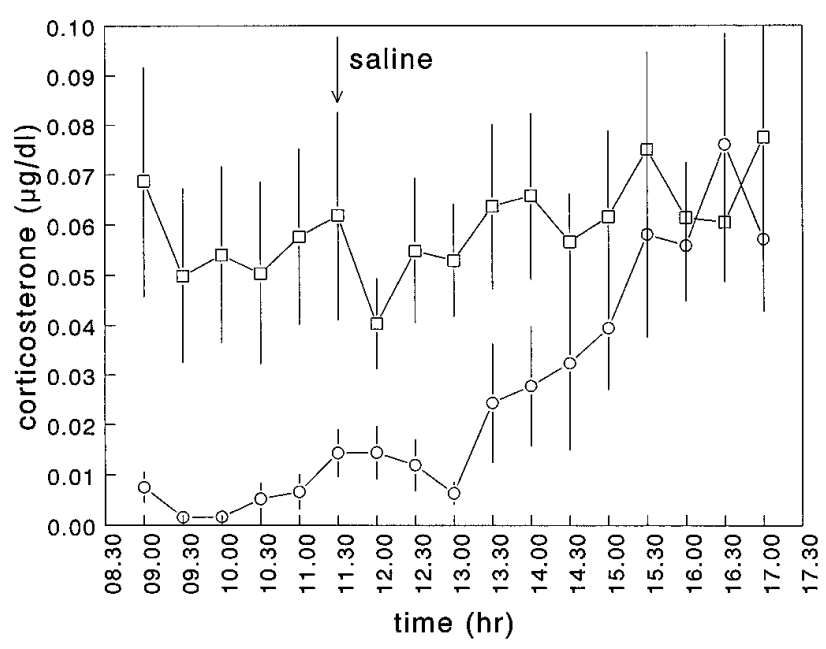

B

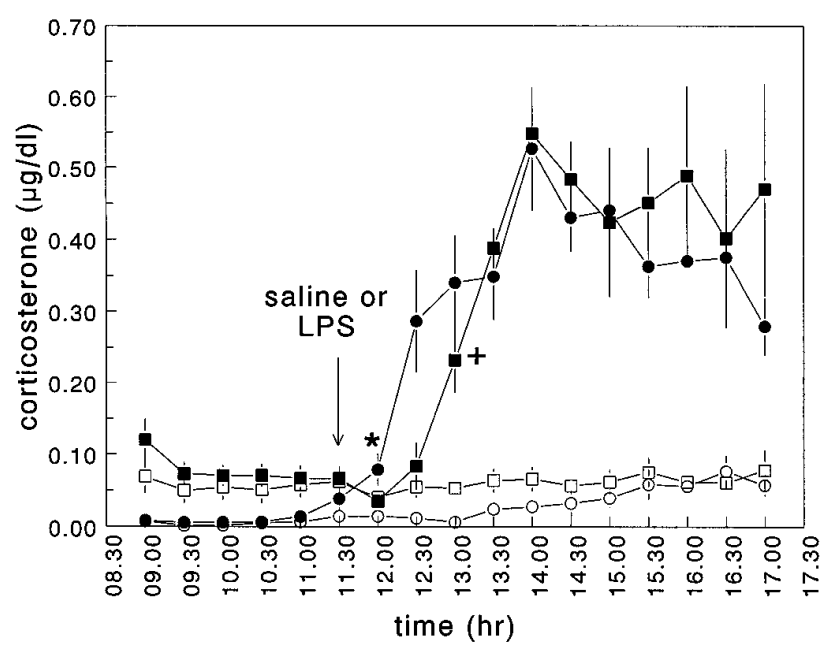

Figure 4. Effect of intraperitoneal administration of saline $(A, B)$ and LPS $(B)(100 \mu \mathrm{g} / \mathrm{kg}$ body weight) on free corticosterone in long-term intracerebroventricularly $\mathrm{CRH}$-infused rats (Protocol B). $A$, Direct comparison of the intraperitoneally saline-treated rats from $B$. Basal corticosterone levels $(A): \bigcirc$, intracerebroventricular vehicle/intraperitoneal saline; $\square$, intracerebroventricular $\mathrm{CRH} /$ intraperitoneal saline. Effect of intraperitoneal injection of LPS $(B)$ : $\mathbf{0}$, intracerebroventricular vehicle/ intraperitoneal LPS; $\mathbf{\square}$, intracerebroventricular $\mathrm{CRH} /$ intraperitoneal LPS. Saline or LPS was injected at 11:30 A.M. on day 7 of the infusion treatment, as indicated by the arrow. Dialysate corticosterone $(\mu \mathrm{g} / \mathrm{dl})$ was measured from 9 A.M. to 5:30 P.M. For more details see Materials and Methods. The time points on the $x$-axis correspond to the time of the day at which collection of the 30 min sample was started. Values represent mean \pm SEM $(n=6-7)$. * First time point of significance for intracerebroventricular vehicle/intraperitoneal LPS compared with intracerebroventricular vehicle/intraperitoneal saline; + , first time point of significance for intracerebroventricular $\mathrm{CRH}$ /intraperitoneal LPS compared with intracerebroventricular CRH/intraperitoneal saline (Student's $t$ test). For additional statistical analyses, see Results.

\section{Effect of intraperitoneal administration of saline and LPS on hippocampal serotonergic neurotransmission and behavioral activity in long-term intracerebroventricularly CRH-treated rats (Protocol B)}

Intraperitoneal administration of LPS significantly increased hippocampal extracellular concentrations of 5-HT in both intracere- broventricularly vehicle- and CRH-infused rats (MANOVA with repeated measures; effect of treatment $F_{(1,19)}=25.93$, significance of $F \leq 0.0005$ ) (Fig. $6 B, D$ ). In the intracerebroventricularly $\mathrm{CRH}$-treated rats, however, the maximal levels of 5-HT reached after LPS were significantly lower than those in the endotoxininjected control rats (MANOVA with repeated measures; interaction between pretreatment and treatment $F_{(1,19)}=7.21$, significance of $F=0.015$ ) (Figs. $6 B, D, 9 A$ ). Intraperitoneal administration of LPS also produced an increase in extracellular 5-HIAA levels (MANOVA with repeated measures design; effect of treatment $F_{(1,20)}=44.21$, significance of $\left.F \leq 0.0005\right)$. Similar levels of 5-HIAA were reached in both infusion groups (MANOVA with repeated measures design; interaction between pretreatment and treatment $F_{(1,20)}=1.80$, significance of $F>$ 0.05 ) (Figs. 7, 9B). The increase in 5-HIAA levels, however, was delayed significantly by $\sim 30 \mathrm{~min}$ in the intracerebroventricularly CRH-infused group (Fig. 7).

Intraperitoneal administration of LPS produced a significant decrease in behavioral activity in both intracerebroventricularly vehicle- and CRH-treated rats (MANOVA with repeated measures design, effect of treatment $F_{(1,21)}=66.79$, significance of $F \leq$ 0.0005; MANOVA with repeated measures design, interaction between pretreatment and treatment $F_{(1,21)}=0.06$, significance of $F>0.05$ ) (Figs. 6B,D, 9C). In the intracerebroventricularly $\mathrm{CRH}$ treated group, however, the behavioral inhibition response was delayed significantly by $\sim 1.5-2.0 \mathrm{hr}$ (Fig. 8).

\section{Effect of intraperitoneal administration of saline and LPS on plasma TNF, IL-1, and IL- 6 concentrations in long-term intracerebroventricularly $\mathrm{CRH}$-treated rats (Protocol C)}

At 3 and $6 \mathrm{hr}$ after saline injection, the plasma bioactivity levels of TNF, IL-1, and IL- 6 were between $30 \mathrm{pg} / \mathrm{ml}$ ( 2 of 16) and below detection, below detection, and between $115 \mathrm{IU} / \mathrm{ml}$ ( 9 of 16) and below detection, respectively. The low detectable concentrations of cytokines in these saline controls were not confined to one time point or pretreatment group (all groups $n=4$ ).

As shown in Table 3, intraperitoneal administration of LPS (100 $\mu \mathrm{g} / \mathrm{kg}$ body weight) caused time-dependent changes in plasma levels of TNF and IL-6 (ANOVA, effect of time; TNF: $F_{(1,17)}=17.63$, significance of $F=0.001$; IL-6: $F_{(1,17)}=13.71$, significance of $F<0.01)$. Plasma levels of TNF and IL-6 were significantly lower at $6 \mathrm{hr}$ than at $3 \mathrm{hr}$ after the administration of LPS; however, IL-1 levels were detectable at 3 but not $6 \mathrm{hr}$ after LPS. Although LPS induced a similar increase in bioactive TNF in intracerebroventricularly vehicle- and CRH-treated rats (ANOVA; effect of pretreatment $F_{(1,17)}=0.50$, significance of $\left.F>0.05\right)$, it induced significantly higher plasma concentrations of IL-1 (Student's $t$ test; $p<0.05$ ) and IL-6 bioactivities (ANOVA; effect of pretreatment $F_{(1,17)}=4.68$, significance of $F<0.05$ ) in the intracerebroventricularly CRH-infused rats than in the control animals (Table 3). Post hoc analyses revealed significantly higher plasma levels of IL- 6 bioactivity at $3 \mathrm{hr}$ but not 6 hr after the endotoxin challenge (Table 3).

\section{DISCUSSION}

Chronically increased brain $\mathrm{CRH}$ levels were found to transiently increase baseline body temperature values and locomotion, to elevate basal HPA axis activity, and to affect hippocampal 5-HT metabolism. Endotoxin stimulation of these rats resulted in blunted fever responses, delayed rises in free glucocorticoid levels, attenuated output of hippocampal 5-HT, and a delayed onset of behavioral inhibition. Thus, chronic CRH hypersecretion seems 
A

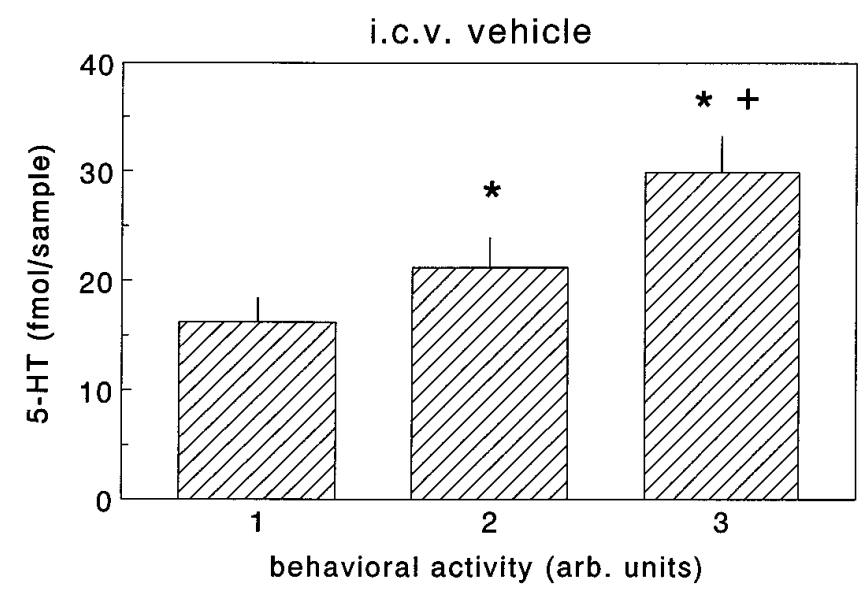

C

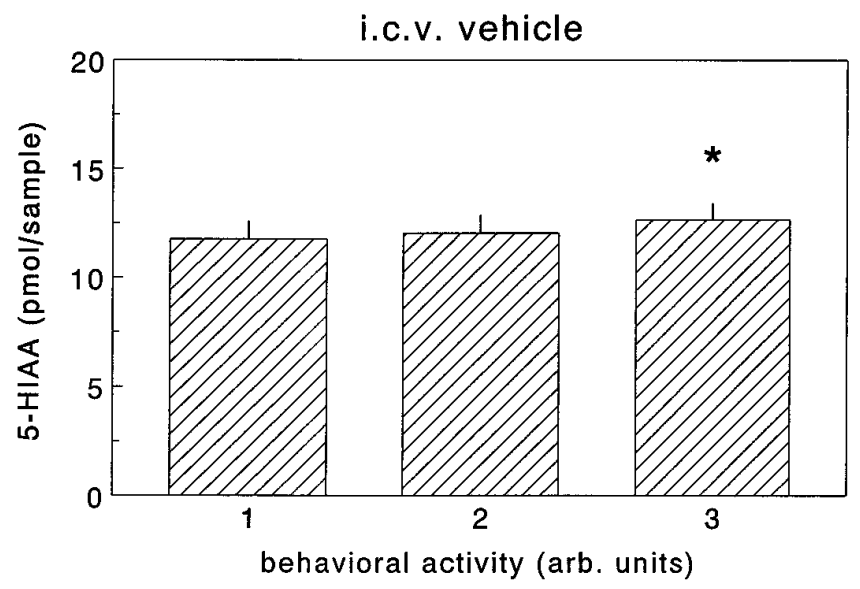

B

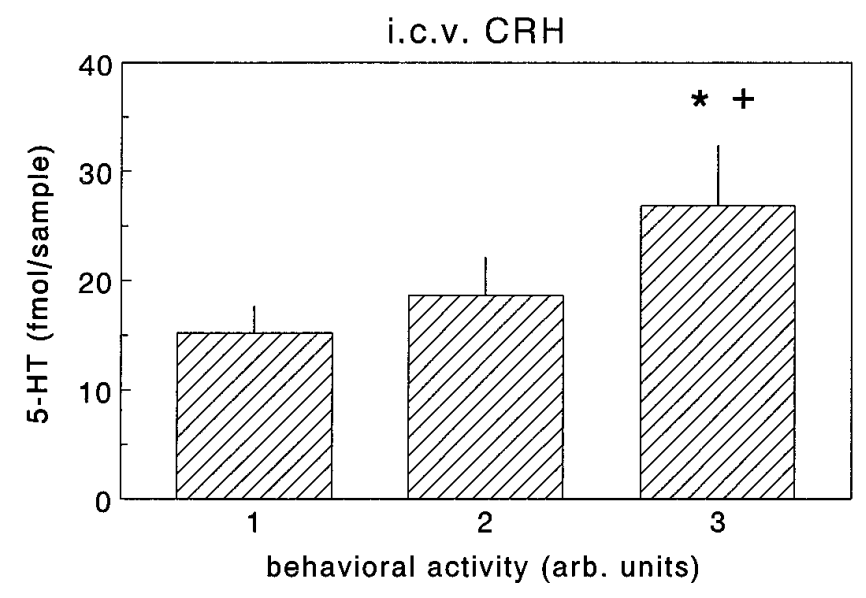

D

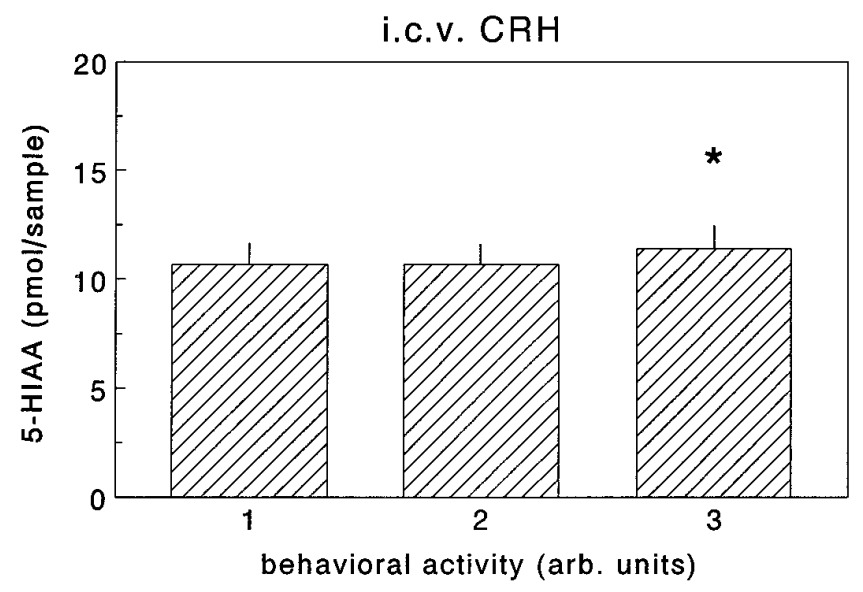

Figure 5. Extracellular concentrations of 5-HT $(A, B)$ and 5-HIAA $(C, D)$ in the hippocampus of intraperitoneally saline-treated rats during different behavioral activity stages as found in experiments described under Protocol B. Data on 5-HT and 5-HIAA are expressed as fmol/sample and pmol/sample, respectively. Values represent mean $\pm \operatorname{SEM}(n=6) .{ }^{*}$, Significantly different from behavioral activity score $1 ;+$, significantly different from behavioral activity score 2 (paired $t$ test; for additional details on the statistical analysis see Materials and Methods).

to result in impaired homeostatic responses to acute stressful stimuli.

Biotelemetric monitoring revealed that continuous intracerebroventricular $\mathrm{CRH}$ infusion increased locomotor activity of the rats during the first $3 \mathrm{~d}$ of the infusion. The behavioral effects of $\mathrm{CRH}$ seem to be attributable to a direct influence on the brain and to be independent of the CRH-induced activation of the HPA axis, because long-term peripheral administration of $\mathrm{CRH}$, which induced similarly elevated levels of corticosterone, had no effect on locomotor activity. The final proof of such a direct central action of $\mathrm{CRH}$, however, awaits further studies using antagonists or antibodies to block potential effects of intracerebroventricularly infused $\mathrm{CRH}$ that possibly leaked to the periphery. Nevertheless, acute intracerebroventricular, but not systemic, injection of $\mathrm{CRH}$ has been reported previously to evoke marked changes in locomotion and other gross behavioral activities in rodents (Dunn

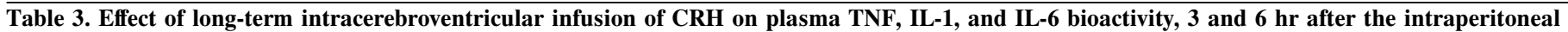
administration of LPS

\begin{tabular}{|c|c|c|c|c|}
\hline & \multicolumn{2}{|l|}{$3 \mathrm{hr}$ after LPS } & \multicolumn{2}{|l|}{$6 \mathrm{hr}$ after LPS } \\
\hline & $\begin{array}{l}\text { Intracerebroventricular } \\
\text { vehicle }\end{array}$ & $\begin{array}{l}\text { Intracerebroventricular } \\
\mathrm{CRH}\end{array}$ & $\begin{array}{l}\text { Intracerebroventricular } \\
\text { vehicle }\end{array}$ & $\begin{array}{l}\text { Intracerebroventricular } \\
\mathrm{CRH}\end{array}$ \\
\hline $\mathrm{TNF}(\mathrm{pg} / \mathrm{ml})$ & $1045 \pm 374(6)$ & $1260 \pm 203(6)$ & $38 \pm 8(5)$ & $158 \pm 52(4)$ \\
\hline IL-1 (IU/ml) & $36.04 \pm 10.13(11)$ & $82.56 \pm 18.06(9)^{*}$ & n.d. & n.d. \\
\hline IL-6 (IU/ml) & $70,928 \pm 22,004(6)$ & $197,654 \pm 59,271(6)^{*}$ & $15,187 \pm 5406(5)$ & $24,949 \pm 8530(4)$ \\
\hline
\end{tabular}

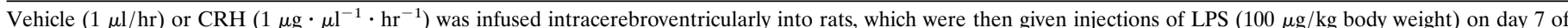

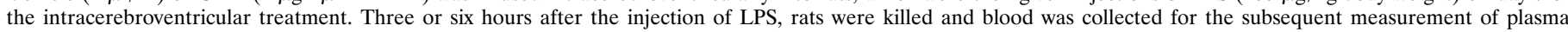

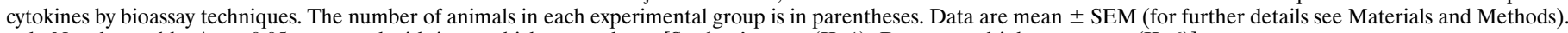
n.d., Not detectable. * $p<0.05$ compared with i.c.v. vehicle-treated rats [Student's $t$ test (IL-1); Duncan multiple range test (IL-6)] 
A

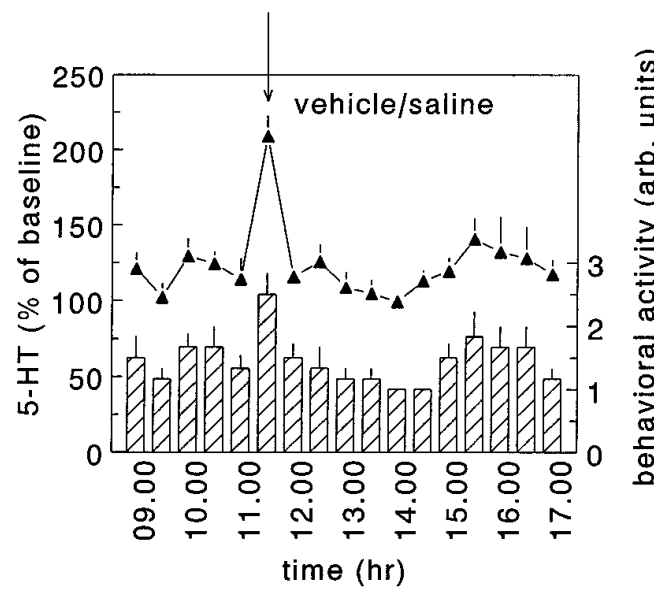

C
B
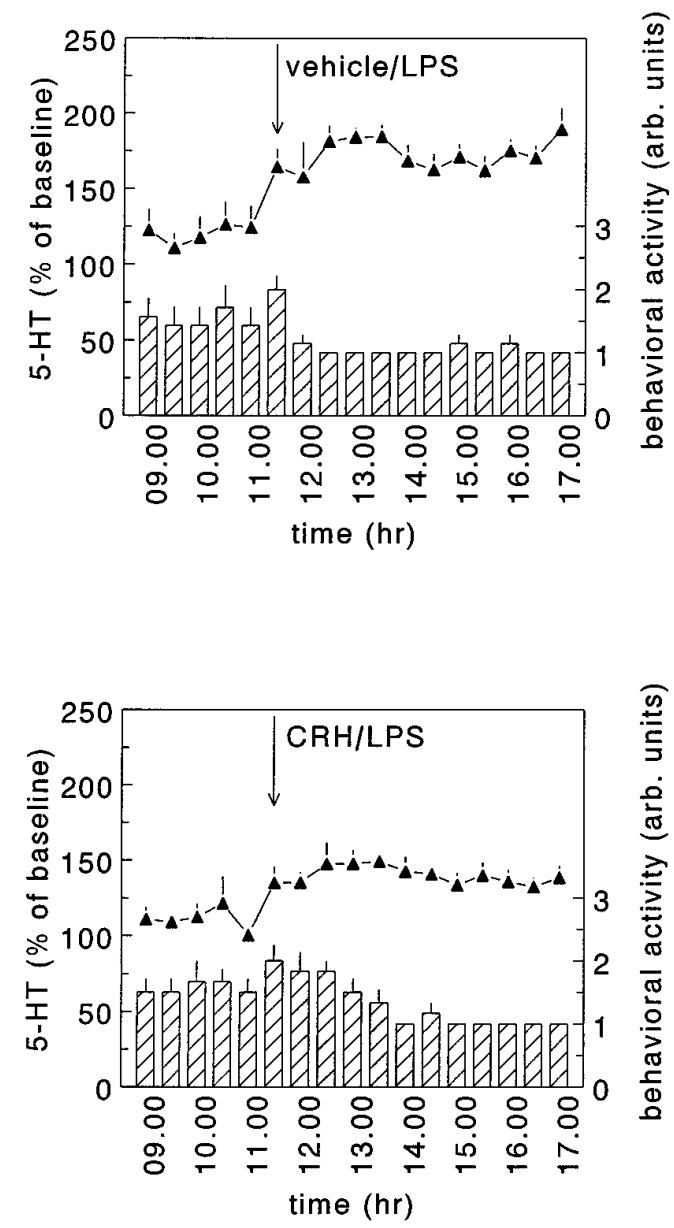

Figure 6. Effects of intraperitoneal administration of saline $(A, C)$ and LPS $(B, D)(100 \mu \mathrm{g} / \mathrm{kg}$ body weight $)$ on hippocampal extracellular levels of 5-HT (\% of baseline; triangles) and behavioral activity (arbitrary units; bars) in long-term intracerebroventricularly vehicle-infused rats $(A, B)$ and intracerebroventricularly CRH-infused rats $(C, D)$ (Protocol B). For more details see Materials and Methods and legend to Figure 4 . Values represent mean \pm SEM $(n=5-7)$. For statistical analyses, see Results.

and Berridge, 1990). Activation of the sympathetic nervous system may play a role in the $\mathrm{CRH}$-evoked hyperlocomotion, because it has been shown that the ganglion blocking agents chlorisondamine and hexamethonium attenuate $\mathrm{CRH}$-induced behavioral changes (Britton and Indyk, 1989).

We report here that chronic intracerebroventricular infusion of $\mathrm{CRH}$ increased core body temperature during the light as well as the dark phase of the diurnal cycle, resulting in a flattening of the circadian rhythm. Differences between the body temperature of intracerebroventricularly $\mathrm{CRH}-$ and control-treated animals lasted until the morning hours of day 6. Also, an acute intracerebroventricular injection of $\mathrm{CRH}$ has been found to increase body temperature (Rothwell, 1990), an effect that was accompanied by increased resting oxygen consumption (Strijbos et al., 1992). The thermogenic effects of CRH are most likely the result of stimulated sympathetic nervous activity (Rothwell, 1990; Fisher, 1993). Accordingly, it has been found that central injection of $\mathrm{CRH}$ increases the firing rate of sympathetic nerves innervating the interscapular brown adipose tissue (Holt and York, 1989; Egawa et al., 1990).

The effects of the intracerebroventricular $\mathrm{CRH}$ infusion on both body temperature and locomotor activity diminished during the course of the treatment period, indicating a progressive desensitization of central CRH effector mechanisms. The possibility of biological inactivation of the CRH solution in the minipump as a cause for the declining and ultimately extinguished effect is unlikely, given the persistent influence of the treatment on HPA axis activity, including day 7 (this study; Labeur et al., 1995). The most probable explanation for the observed decline may be changes on the level of $\mathrm{CRH}$ receptors. Adrenalectomy and chronic stress, both resulting in increased levels of brain $\mathrm{CRH}$, decrease $\mathrm{CRH}$ receptor density and $\mathrm{CRH}$ receptor mRNA concentrations in the anterior pituitary (De Souza et al., 1985; Hauger et al., 1988; Luo et al., 1995; Makino et al., 1995). It has been described that chronic stress decreases $\mathrm{CRH}$ receptor binding in the frontal cortex and hypothalamus (Anderson et al., 1993). Moreover, peripheral infusion of CRH for $\sim 2 \mathrm{~d}$ reduces pituitary CRH receptor concentrations (Tizabi and Aguilera, 1992). Alternatively, changes in CRH binding protein activity and/or clearance of CRH may have affected CRH bioavailability (Oldfield et al., 1985; Behan et al., 1995).

As is well described in the literature (Kluger, 1991), intraperitoneal administration of LPS in control animals produced a pronounced increase in body temperature. Compared with control 


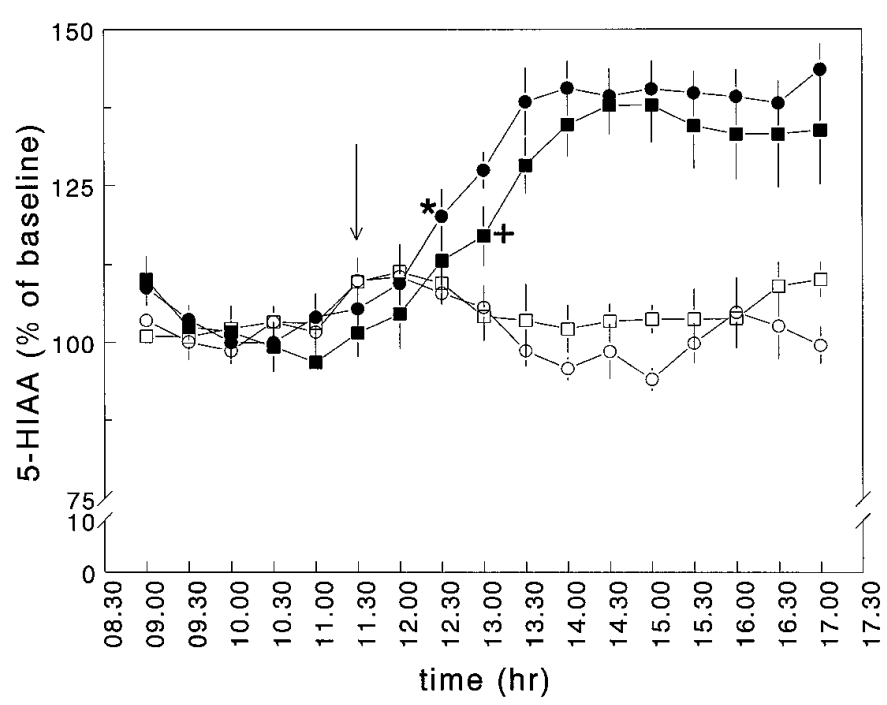

Figure 7. Effects of intraperitoneal administration of saline and LPS (100 $\mu \mathrm{g} / \mathrm{kg}$ body weight) on hippocampal extracellular levels of 5-HIAA (\% of baseline; Protocol B). There were four treatment groups: intracerebroventricular vehicle/intraperitoneal saline $(\bigcirc)$; intracerebroventricular vehicle/intraperitoneal LPS (๑); intracerebroventricular CRH/intraperitoneal saline $(\square)$; intracerebroventricular CRH/intraperitoneal LPS (ם). For more details, see Materials and Methods and legend to Figure 4. Values represent mean $\pm \operatorname{SEM}(n=5-7) .{ }^{*}$, First time point of significance for intracerebroventricular vehicle/intraperitoneal LPS compared with intracerebroventricular vehicle/intraperitoneal saline; + , first time point of significance for intracerebroventricular CRH/intraperitoneal LPS compared with intracerebroventricular $\mathrm{CRH} /$ intraperitoneal saline (Student's $t$ test). For additional statistical analyses, see Results.

animals, however, intracerebroventricularly CRH-treated rats developed a significantly attenuated LPS-induced fever response. Given that $\mathrm{CRH}$ is an important central intermediary of the principal endotoxin mediator IL-1, the observed blunted pyrogenic response after chronic CRH treatment is most likely attributable to desensitization of $\mathrm{CRH}$ receptor systems involved in triggering sympathetic outflow. The blunted endotoxin-induced fever response after the $\mathrm{CRH}$ treatment seemed not to be the result of elevated corticosterone levels, because subcutaneously $\mathrm{CRH}$-infused rats (having a similar glucocorticoid load as intracerebroventricularly CRH-treated animals) showed no attenuated LPS-induced fever responses.

We found that chronic intracerebroventricular CRH treatment resulted in continuously elevated free corticosterone levels without any diurnal variation, which is a condition also observed during chronic stress (Owens and Nemeroff, 1991) and stressrelated disorders, such as major depression (Owens and Nemeroff, 1991; Holsboer and Barden, 1996). The LPS treatment evoked a marked HPA axis activation, which is in agreement with earlier studies (Bateman et al., 1989; Linthorst et al., 1995b; Besedovsky and Del Rey, 1996). In the intracerebroventricularly CRH-treated rats, LPS also induced a pronounced rise in dialysate corticosterone to levels similar to those found in the control animals. This is a striking observation for two reasons. (1) The elevated circulating glucocorticoid levels ( $\sim 12 \mu \mathrm{g} / \mathrm{dl}$ plasma) (Labeur et al., 1995) were expected to suppress the synthesis of LPS-induced HPA axis-activating proinflammatory cytokines (e.g., IL-1, IL-6) (Munck and Guyre, 1991) (such inhibition was not observed; see below) and to exert enhanced negative feedback at the level of the anterior pituitary and the hypothalamic PVN, thereby attenuating the capacity of stimulus-evoked HPA axis activation. Evidently,

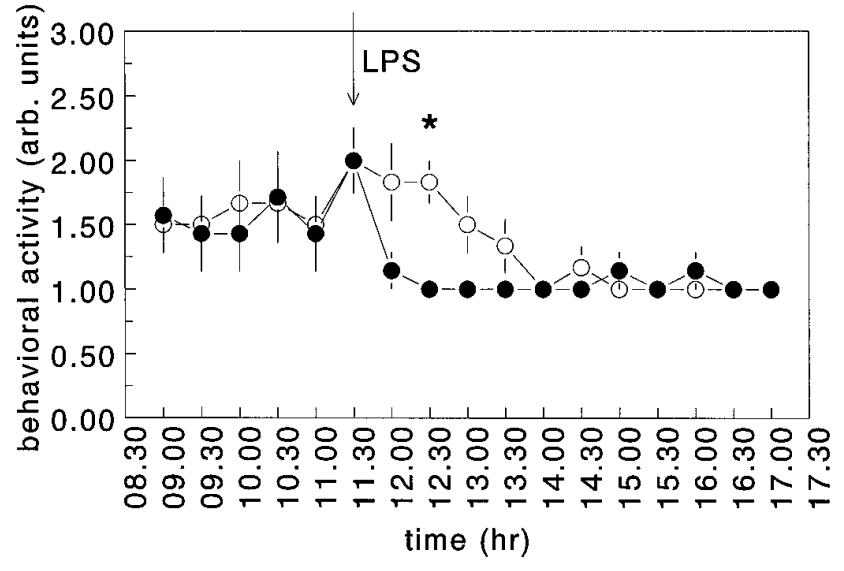

Figure 8. Effects of intraperitoneal administration of LPS $(100 \mu \mathrm{g} / \mathrm{kg}$ body weight) on behavioral activity (arbitrary units) in long-term intracerebroventricularly vehicle-infused rats $(\mathbf{O})$ and intracerebroventricularly $\mathrm{CRH}$-infused rats $(\bigcirc)$ (direct comparison of behavioral activity data of Fig. $6 B, D$ ). LPS was injected at 11:30 A.M. as indicated by the arrow. For additional details see legends to Figures 4 and 6 . Values represent mean \pm SEM $(n=6-7)$. *, Significantly different from intracerebroventricularly vehicle-/intraperitoneally LPS-treated rats (Student's $t$ test). For additional statistical analyses, see Results.

endogenous corticotrophin secretagogues (e.g., CRH) known to be mediators of LPS- and IL-1-induced HPA axis activation (Berkenbosch et al., 1987; Sapolsky et al., 1987; Rivier, 1993), could still be triggered by endotoxin stimulation despite the (exogenously evoked) hypercortisolemic state of the animal. (2) Chronic CRH treatment-evoked downregulation of anterior pituitary $\mathrm{CRH}$ receptors would be expected to blunt an endotoxininduced ACTH response. The HPA axis response, however, in terms of free corticosterone levels was clearly not blunted, but was delayed by $\sim 1 \mathrm{hr}$. This finding suggests that HPA axis activation remained possible after long-term intracerebroventricular $\mathrm{CRH}$ treatment, but as a result of various factors (e.g., changes in endogenous corticotrophin secretagogues secretion, anterior pituitary $\mathrm{CRH}$ and other receptors, and/or cytokine production) apparently the net effect was a glucocorticoid response that had a normal amplitude but was delayed significantly. Physiologically, the consequence of such an impaired response may be that glucocorticoid-facilitated and glucocorticoid-regulated processes are executed (too) late (Wiegers et al., 1995).

Hippocampal extracellular 5-HT (and to a much lesser extent 5-HIAA) levels varied in parallel with behavioral activity, which is a finding already reported and discussed in our previous studies (Linthorst et al., 1994, 1995a). No differences were found in hippocampal extracellular fluctuations in 5-HT and 5-HIAA levels as a function of behavioral activity between vehicle- and $\mathrm{CRH}$-treated rats. Until now, the effects of CRH on serotonergic neurotransmission have hardly been studied. Lavicky and Dunn (1993) have shown that intracerebroventricularly applied CRH increases extracellular levels of 5-HIAA in the rat medial hypothalamus and the prefrontal cortex, whereas other studies revealed no effect on 5-HT turnover in several brain structures in rats (Fekete et al., 1985) and mice (Dunn and Berridge, 1987). We have found that acute intracerebroventricular administration of CRH profoundly increases hippocampal extracellular 5-HT and 5-HIAA levels (A. C. E. Linthorst and J. M. H. M. Reul, unpublished observations), presumably via receptors located on raphe neurons and/or on neurons projecting to the raphe-hippocampal 
A

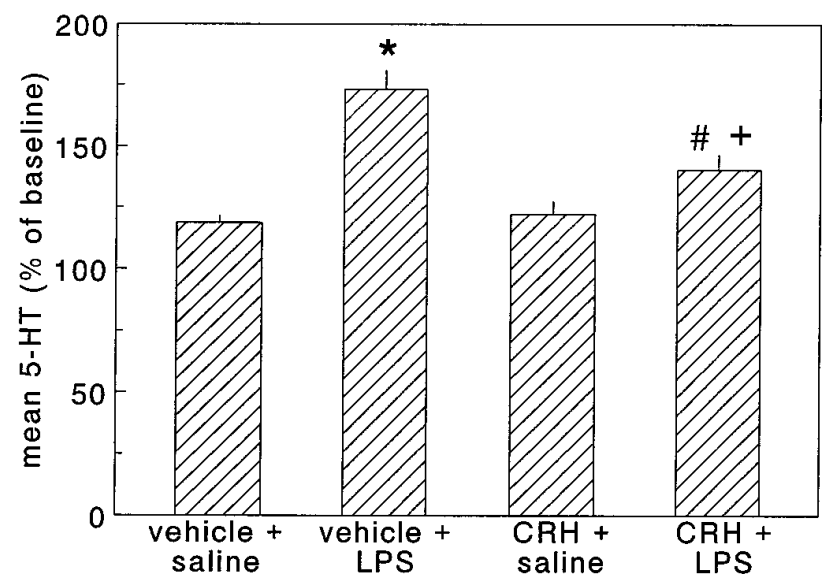

C

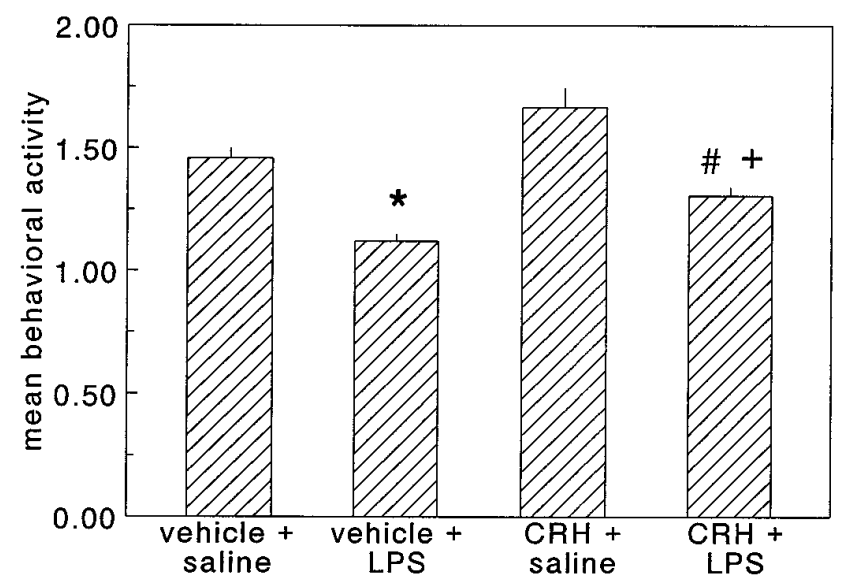

B

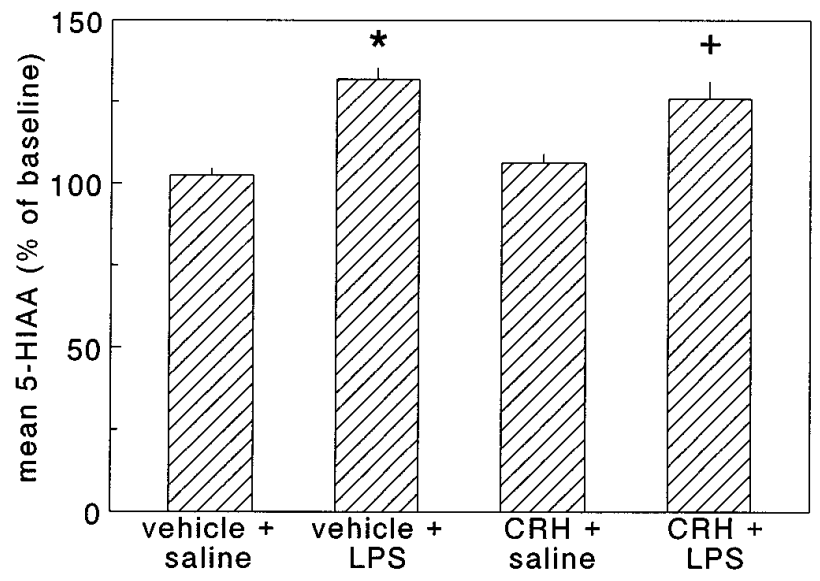

D

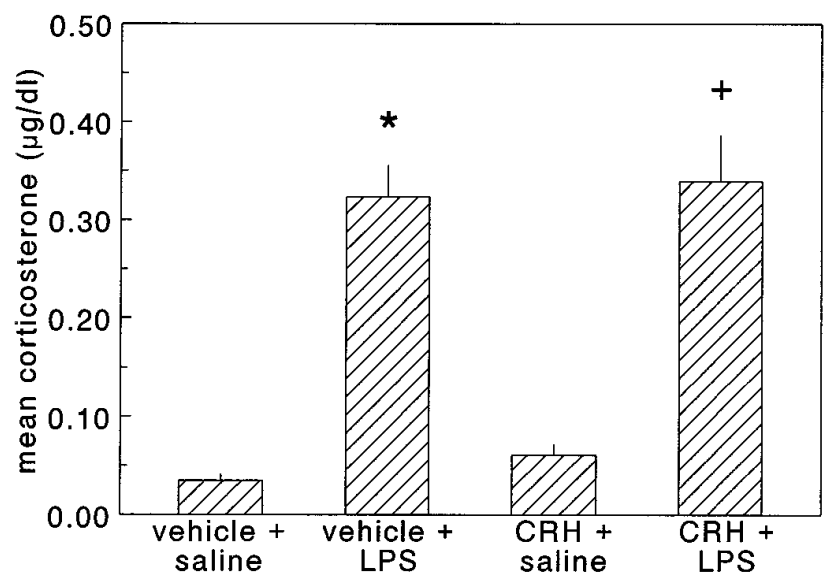

Figure 9. Mean values of hippocampal extracellular concentrations of 5-HT $(A), 5$-HIAA $(B)$, and dialysate corticosterone $(D)$, and of behavioral activity scores $(C)$ for the period after the intraperitoneal injection of saline or LPS in long-term intracerebroventricularly vehicle- and CRH-treated rats as deducted from the time curves presented in Figures 4, 6, and 7. Rats were treated in four experimental groups: intracerebroventricular vehicle/ intraperitoneal saline, intracerebroventricular vehicle/intraperitoneal LPS, intracerebroventricular CRH/intraperitoneal saline, and intracerebroventricular CRH/intraperitoneal LPS. Samples were collected every $30 \mathrm{~min}$ as described under Protocol B. Extracellular levels of 5-HT and 5-HIAA are expressed as \% of baseline, dialysate corticosterone as $\mu \mathrm{g} / \mathrm{dl}$, and behavioral activity scores as arbitrary units (for more details see Materials and Methods). *, Significantly different from intracerebroventricularly vehicle-/intraperitoneally saline-treated rats; +, significantly different from intracerebroventricularly $\mathrm{CRH}$-/intraperitoneally saline-treated rats; \#, significantly different from intracerebroventricularly vehicle-/intraperitoneally LPS-treated rats (Duncan multiple range test).

system (Chalmers et al., 1995, 1996). These effects are in line with reports showing changes in midbrain tryptophan hydroxylase activity after acute intracerebroventricular $\mathrm{CRH}$ administration (Singh et al., 1992). Given that the microdialysis experiments presented here were performed on day 7 of $\mathrm{CRH}$ treatment, the absence of a difference in baseline 5-HT and 5-HIAA strongly suggests pertinent regulatory changes in 5-HT metabolism as a result of the chronic $\mathrm{CRH}$ treatment.

This notion is supported by the observation that the hippocampal serotonergic response to LPS in intracerebroventricular CRHinfused rats was diminished significantly. The responses in the control rats agreed with those published previously (Linthorst et al., 1995b, 1996). The altered 5-HT responses to endotoxin during $\mathrm{CRH}$ treatment seem to emphasize further that chronic $\mathrm{CRH}$ hypersecretion generates comprehensive changes in brain 5-HT metabolism. Additional factors involved in the impaired 5-HT response to LPS may include changes in brain IL-1 expression, because this cytokine is one of the main mediators of the LPS effects on hippocampal 5-HT (Linthorst et al., 1995b). The differential glucocorticoid responses may present another factor in view of the described interactions between these hormones and serotonergic neurotransmission (De Kloet, 1991). The exact modes of interaction are still not elucidated, however, making an in-depth analysis impossible at present. Thus, it remains unclear whether corticosterone plays a role in the altered LPS-induced 5-HT response in the intracerebroventricularly $\mathrm{CRH}$-treated rats.

The CRH-induced changes in 5-HT metabolism and resultant impaired 5-HT responses to LPS may cause changes in the appropriate behavioral response (i.e., behavioral inhibition) of the animal. There is strong evidence that serotonin at the septohippocampal level is involved in the execution of behavioral inhibition after exposure of the animal to aversive stimuli (Gray, 1982). Thus, given that enhanced hippocampal serotonergic neurotransmission after LPS may participate in the behavioral inhibition response during sickness, it seems that the delayed onset of behavioral inhibition (by 1.5-2.0 hr) in the $\mathrm{CRH}$-treated rats 
results from deficient rises in hippocampal 5-HT in these animals. Because sickness behavior (and also fever) are important host defense responses, it may be concluded that chronic CRH hypersecretion hampers the execution of appropriate defense mechanisms during disease and other stressful situations.

To elucidate the role of cytokines in the altered endotoxininduced physiological, neurochemical, and behavioral responses, plasma IL-1, IL-6, and TNF bioactivities were measured. We found that the levels of IL-1 and IL-6 were enhanced substantially in the CRH-treated rats at $3 \mathrm{hr}$ after LPS, whereas TNF bioactivity was unaltered. These findings were contrary to expectations, because of the well known negative regulation of these cytokines by glucocorticoid hormones (Beutler et al., 1986; Lee et al., 1988; Munck and Guyre, 1991) but were consistent with the observation of increased IL- $1 \beta$ mRNA expression in spleen macrophages of these animals (Labeur et al., 1995). Thus, the observed LPSinduced changes in circulating cytokine levels in CRH-treated rats can hardly be held responsible for the impaired neurochemical, physiological, and behavioral responses to endotoxin in these animals. The increased production of IL-1 and IL-6, however, could be interpreted as a compensatory measure aimed at counteracting the hypercortisolemic and desensitized CRH receptor state of the intracerebroventricularly CRH-treated rat. This seems a sensible way to uphold certain pivotal responses to stressful challenges but is potentially dangerous as well, given that these cytokines are known to participate in pathologies such as septic shock and tissue degeneration (Dinarello, 1991).

The data show that chronically elevated CRH levels in the brain generate changes in autonomic and HPA axis responsiveness to an acute challenge. Moreover, this condition affects serotonergic neurotransmission that evolves as a defective serotonergic and behavioral response to an acute stimulus. Such aberrant responses, at least in part, are known to occur in stress-related disorders such as major depression. Therefore, this study has provided evidence favoring a principal role of CRH in the etiology of stress-related disorders.

\section{REFERENCES}

Anderson SM, Kant GJ, De Souza EB (1993) Effects of chronic stress on anterior pituitary and brain corticotropin-releasing factor receptors. Pharmacol Biochem Behav 44:755-761.

Bateman A, Singh A, Kral T, Solomon S (1989) The immunehypothalamic-pituitary-adrenal axis. Endocr Rev 10:92-112.

Behan DP, Heinrichs SC, Troncoso JC, Liu XJ, Kawas CH, Ling N, De Souza EB (1995) Displacement of corticotropin releasing factor from its binding protein as a possible treatment for Alzheimer's disease. Nature 378:284-287.

Berkenbosch F, Van Oers J, Del Rey A, Tilders F, Besedovsky H (1987) Corticotropin-releasing factor-producing neurons in the rat activated by interleukin-1. Science 238:524-526.

Besedovsky HO, Del Rey A (1996) Immune-neuro-endocrine interactions: facts and hypotheses. Endocr Rev 17:64-102.

Beutler B, Krochin N, Milsark IW, Luedke C, Cerami A (1986) Control of cachectin (tumor necrosis factor) synthesis: mechanisms of endotoxin resistance. Science 232:977-980.

Britton DR, Indyk E (1989) Effects of ganglionic blocking agents on behavioral responses to centrally administered CRF. Brain Res 478:205-210.

Britton DR, Koob GF, Rivier J, Vale W (1982) Intraventricular corticotropin-releasing factor enhances behavioral effects of novelty. Life Sci 31:363-367.

Brown MR, Fisher LA, Spiess J, Rivier C, Rivier J, Vale W (1982) Corticotropin-releasing factor: actions on the sympathetic nervous system and metabolism. Endocrinology 111:928-931.

Chalmers DT, Lovenberg TW, De Souza EB (1995) Localization of novel corticotropin-releasing factor receptor $\left(\mathrm{CRF}_{2}\right)$ mRNA expression to specific subcortical nuclei in rat brain: comparison with $\mathrm{CRF}_{1}$ receptor mRNA expression. J Neurosci 15:6340-6350.

Chalmers DT, Lovenberg TW, Grigoriadis DE, Behan DP, De Souza EB (1996) Corticotrophin-releasing factor receptors: from molecular biology to drug design. Trends Pharmacol Sci 17:166-172.

Dallman MF, Akana SF, Cascio CS, Darlington DN, Jacobson L, Levin N (1987) Regulation of ACTH secretion: variations on a theme of B. Recent Prog Horm Res 43:113-173.

De Kloet ER (1991) Brain corticosteroid receptor balance and homeostatic control. Front Neuroendocrinol 12:95-164.

De Souza EB, Insel TR, Perrin MH, Rivier J, Vale WW, Kuhar MJ (1985) Differential regulation of corticotropin-releasing factor receptors in anterior and intermediate lobes of pituitary and in brain following adrenalectomy in rats. Neurosci Lett 56:121-128.

Dinarello CA (1991) Interleukin-1 and interleukin-1 antagonism. Blood 77:1627-1652.

Dunn AJ, Berridge CW (1987) Corticotropin-releasing factor administration elicits a stress-like activation of cerebral catecholaminergic systems. Pharmacol Biochem Behav 27:685-691.

Dunn AJ, Berridge CW (1990) Physiological and behavioral responses to corticotropin-releasing factor administration: is CRF a mediator of anxiety or stress responses. Brain Res Rev 15:71-100.

Egawa M, Yoshimatsu H, Bray GA (1990) Preoptic area injection of corticotropin-releasing hormone stimulates sympathetic activity. Am J Physiol 259:R799-R806.

Fekete M, Balazs M, Telegdy G, Schally AV (1985) Effects of intracerebroventricular administration of ovine corticotropin-releasing factor (CRF 1-41) on passive avoidance behaviour: lack of influence on monoamine contents of limbic brain areas. Neuropeptides 6:283-292.

Fisher LA (1993) Central actions of corticotropin-releasing factor on autonomic nervous activity and cardiovascular functioning. Ciba Found Symp 172:243-253.

Gold PW, Loriaux DL, Roy A, Kling MA, Calabrese JR, Kellner CH, Nieman LK, Post RM, Pickar D, Gallucci W, Augerinos P, Paul S, Oldfield EH, Cutler Jr GB, Chrousos GP (1986) Responses to corticotropin-releasing hormone in the hypercortisolism of depression and Cushing's disease: pathophysiologic and diagnostic implications. New Engl J Med 314:1329-1335.

Gray JA (1982) The role of the ascending projections to the septohippocampal system. In: The neurophysiology of anxiety: an enquiry into the functions of the septo-hippocampal system (Broadbent DE, McGaugh JL, Mackintosh NJ, Posner MI, Tulving E, Weiskrantz L, eds), pp 300-373. Oxford: Clarendon.

Hauger RL, Millan MA, Lorang M, Harwood JP, Aguilera G (1988) Corticotropin-releasing factor receptors and pituitary adrenal responses during immobilization stress. Endocrinology 123:396-405.

Holsboer F, Barden N (1996) Antidepressants and hypothalamic pituitary adrenocortical regulation. Endocr Rev 17:187-205.

Holsboer F, Von Bardeleben U, Gerken A, Stalla GK, Muller OA (1984) Blunted corticotropin and normal cortisol response to human corticotropin-releasing factor in depression. New Engl J Med 311:1127.

Holt I, Cooper RG, Hopkins SJ (1991) Relationships between local inflammation, interleukin- 6 concentration and the acute phase protein response in arthritis patients. Eur J Clin Invest 21:479-484.

Holt SJ, York DA (1989) The effects of adrenalectomy, corticotropin releasing factor and vasopressin on the sympathetic firing rate of nerves to interscapular brown adipose tissue in the Zucker rat. Physiol Behav 45:1123-1129.

Hopkins SJ, Humphreys M (1990) Bioassay of interleukin-1 in serum and plasma following removal of inhibitory activity with polyethylene glycol. J Immunol Methods 133:127-131.

Kluger MJ (1991) Fever: role of pyrogens and cryogens. Physiol Rev 71:93-127.

Labeur MS, Arzt E, Wiegers GJ, Holsboer F, Reul JMHM (1995) Longterm intracerebroventricular corticotropin-releasing hormone administration induces distinct changes in rat splenocyte activation and cytokine expression. Endocrinology 136:2678-2688.

Lavicky J, Dunn AJ (1993) Corticotropin-releasing factor stimulates catecholamine release in hypothalamus and prefrontal cortex in freely moving rats as assessed by microdialysis. J Neurochem 60:602-612.

Lee SW, Tsou AP, Chan H, Thomas J, Petrie K, Eugui EM, Allison AC (1988) Glucocorticoids selectively inhibit the transcription of the interleukin 1 beta gene and decrease the stability of interleukin 1 beta mRNA. Proc Natl Acad Sci USA 85:1204-1208.

Linthorst ACE, Flachskamm C, Holsboer F, Reul JMHM (1994) Local 
administration of recombinant human interleukin-1 beta in the rat hippocampus increases serotonergic neurotransmission, hypothalamicpituitary-adrenocortical axis activity, and body temperature. Endocrinology 135:520-532.

Linthorst ACE, Flachskamm C, Holsboer F, Reul JMHM (1995a) Intraperitoneal administration of bacterial endotoxin enhances noradrenergic neurotransmission in the rat preoptic area: relationship with body temperature and hypothalamic-pituitary-adrenocortical axis activity. Eur J Neurosci 7:2418-2430.

Linthorst ACE, Flachskamm C, Müller-Preuss P, Holsboer F, Reul JMHM (1995b) Effect of bacterial endotoxin and interleukin-1 beta on hippocampal serotonergic neurotransmission, behavioral activity, and free corticosterone levels: an in vivo microdialysis study. J Neurosci 15:2920-2934.

Linthorst ACE, Flachskamm C, Holsboer F, Reul JMHM (1996) Activation of serotonergic and noradrenergic neurotransmission in the rat hippocampus after peripheral administration of bacterial endotoxin: involvement of the cyclo-oxygenase pathway. Neuroscience 72:989-997.

Luheshi G, Miller AJ, Brouwer S, Dascombe MJ, Rothwell NJ, Hopkins SJ (1996) Interleukin-1 receptor antagonist inhibits endotoxin fever and systemic interleukin-6 induction in the rat. Am J Physiol 33:E91-E95.

Luo X, Kiss A, Rabadandiehl C, Aguilera G (1995) Regulation of hypothalamic and pituitary corticotropin-releasing hormone receptor messenger ribonucleic acid by adrenalectomy and glucocorticoids. Endocrinology 136:3877-3883.

Maes M, Meltzer HY (1995) The serotonin hypothesis of major depression. In: Psychopharmacology: The fourth generation of progress (Bloom FE, Kupfer DJ, eds), pp 933-944. New York: Raven.

Makino S, Schulkin J, Smith MA, Pacak K, Palkovits M, Gold PW (1995) Regulation of corticotropin-releasing hormone receptor messenger ribonucleic acid in the rat brain and pituitary by glucocorticoids and stress. Endocrinology 136:4517-4525.

Munck A, Guyre PM (1991) Glucocorticoids and immune function. In: Psychoneuroimmunology (Ader R, Felten DS, Cohen N, eds), pp 447 474. San Diego: Academic.

Nemeroff CB, Widerlov E, Bissette G, Walleus H, Karlsson I, Eklund K, Kilts CD, Loosen PT, Vale W (1984) Elevated concentrations of CSF corticotropin-releasing factor-like immunoreactivity in depressed patients. Science 226:1342-1344.

Oldfield EH, Schulte HM, Chrousos GP, Rock JP, Kornblith PL, O’Neill DL, Poplack DG, Gold PW, Cutler Jr GB, Loriaux L (1985) Active clearance of corticotropin-releasing factor from the cerebrospinal fluid. Neuroendocrinology 40:84-87.

Owens MJ, Nemeroff CB (1991) Physiology and pharmacology of corticotropin-releasing factor. Pharmacol Rev 43:425-473.

Owens MJ, Nemeroff CB (1993) The role of corticotropin-releasing factor in the pathophysiology of affective and anxiety disorders: laboratory and clinical studies. Ciba Found Symp 172:296-308.
Paxinos G, Watson C (1982) The rat brain in stereotactic coordinates. Sydney: Academic.

Raadsheer FC, Hoogendijk WJG, Stam FC, Tilders FJH, Swaab DF (1994) Increased numbers of corticotropin-releasing hormone expressing neurons in the hypothalamic paraventricular nucleus of depressed patients. Neuroendocrinology 60:436-444.

Raadsheer FC, Van Heerikhuize JJ, Lucassen PJ, Hoogendijk WJG, Tilders FJH, Swaab DF (1995) Corticotropin-releasing hormone mRNA levels in the paraventricular nucleus of patients with Alzheimer's disease and depression. Am J Psychiatry 152:1372-1376.

Rivier C (1993) Effect of peripheral and central cytokines on the hypothalamic-pituitary-adrenal axis of the rat. Ann NY Acad Sci 697:97-105.

Rivier C, Vale W (1983) Modulation of stress-induced ACTH release by corticotropin-releasing factor, catecholamines and vasopressin. Nature 305:325-327.

Rivier C, Rivier J, Vale W (1982) Inhibition of adrenocorticotropic hormone secretion in the rat by immunoneutralization of corticotropinreleasing factor. Science 218:377-379.

Rothwell NJ (1989) CRF is involved in the pyrogenic and thermogenic effects of interleukin 1 beta in the rat. Am J Physiol 256:E111-E115.

Rothwell NJ (1990) Central effects of CRF on metabolism and energy balance. Neurosci Biobehav Rev 14:263-271.

Sapolsky R, Rivier C, Yamamoto G, Plotsky P, Vale W (1987) Interleukin-1 stimulates the secretion of hypothalamic corticotropinreleasing factor. Science 238:522-524.

Singh VB, Hao-Phan T, Corley KC, Boadle-Biber MC (1992) Increase in cortical and midbrain tryptophan hydroxylase activity by intracerebroventricular administration of corticotropin releasing factor: block by adrenalectomy, by RU 38486 and by bilateral lesions to the central nucleus of the amygdala. Neurochem Int 20:81-92.

Strijbos PJ, Hardwick AJ, Relton JK, Carey F, Rothwell NJ (1992) Inhibition of central actions of cytokines on fever and thermogenesis by lipocortin-1 involves CRF. Am J Physiol 263:E632-E636.

Sutton RE, Koob GF, Le Moal M, Rivier J, Vale W (1982) Corticotropin releasing factor produces behavioural activation in rats. Nature 297:331-333.

Tizabi Y, Aguilera G (1992) Desensitization of the hypothalamicpituitary-adrenal axis following prolonged administration of corticotropin-releasing hormone or vasopressin. Neuroendocrinology 56:611-618.

Vale W, Spiess J, Rivier C, Rivier J (1981) Characterization of a 41residue ovine hypothalamic peptide that stimulates secretion of corticotropin and beta-endorphin. Science 213:1394-1397.

Wiegers GJ, Labeur MS, Stec IEM, Klinkert WEF, Holsboer F, Reul JMHM (1995) Glucocorticoids accelerate anti-T cell receptor-induced $\mathrm{T}$ cell growth. J Immunol 155:1893-1902. 